\title{
The nonlinear dynamic behaviour of tapered laminated plates subjected to blast loading
}

\author{
Sedat Susler ${ }^{\mathrm{a}}$, Halit S. Turkmen ${ }^{\mathrm{a}, *}$ and Zafer Kazanc1 ${ }^{\mathrm{b}}$ \\ ${ }^{a}$ Faculty of Aeronautics and Astronautics, Istanbul Technical University, Maslak, Istanbul, Turkey \\ b Aerospace Engineering Department, Turkish Air Force Academy, Yesilyurt, Istanbul, Turkey
}

Received 26 June 2011

Revised 24 October 2011

\begin{abstract}
In this study, the geometrically nonlinear dynamic behaviour of simply supported tapered laminated composite plates subjected to the air blast loading is investigated numerically. In-plane stiffness, inertia and the geometric nonlinearity effects are considered in the formulation of the problem. The equations of motion for the tapered laminated plate are derived by the use of the virtual work principle. Approximate solution functions are assumed for the space domain and substituted into the equations of motion. Then, the Galerkin method is used to obtain the nonlinear algebraic differential equations in the time domain. The resulting equations are solved by using the finite difference approximation over the time. The effects of the taper ratio, the stacking sequence and the fiber orientation angle on the dynamic response are investigated. The displacement-time and strain-time histories are obtained on certain points in the tapered direction. The results obtained by using the present method are compared with the ones obtained by using a commercial finite element software ANSYS. The results are found to be in an agreement. The method presented here is able to determine the nonlinear dynamic response of simply supported tapered laminated plates to the air blast loading accurately.
\end{abstract}

Keywords: Tapered plate, blast loading, laminated composite plate, large deflection, nonlinear analysis, finite element method

\section{Introduction}

The plate and shell structures are used in many engineering applications. The tapered plates are particularly used to obtain an optimized structure by saving the weight. Predicting the dynamic response of plates subjected to time dependent loads is important for the design of aerospace and marine structures. Several studies have been done on both linear and nonlinear analysis of isotropic and composite flat plates subjected to time dependent loads such as air blast. In a paper on the effect of the blast load, the nonlinear damped vibration of a simply supported laminated composite plate is studied theoretically [1]. In the other two studies, in-plane stiffness and inertias are considered in the analytical solution of the laminated composite plate under the blast load [2,3]. In a study on the effect of blast loading, the dynamic response of sandwich panels is investigated [4]. The nonlinear structural response of laminated composites subjected to blast loading is also investigated experimentally and theoretically [5, 6]. The theoretical results are found to be in an agreement with the experimental ones qualitatively. The effect of the pulses of different shapes on the dynamic response of simply-supported orthotropic plates is investigated in one of the studies on the blast loading [7]. In another study, the response of stiffened and unstiffened plates subjected to blast loading is analyzed by using a single energy based formulation [8]. Theoretical and experimental results are compared for geometrically nonlinear vibrations of rectangular plates with different boundary conditions [9,10].

${ }^{*}$ Corresponding author: Halit S. Turkmen, Faculty of Aeronautics and Astronautics, Istanbul Technical University, Maslak, Istanbul 34469, Turkey. Tel.: +90 212 2853196; Fax: +90 212 2853139; E-mail: halit@itu.edu.tr. 


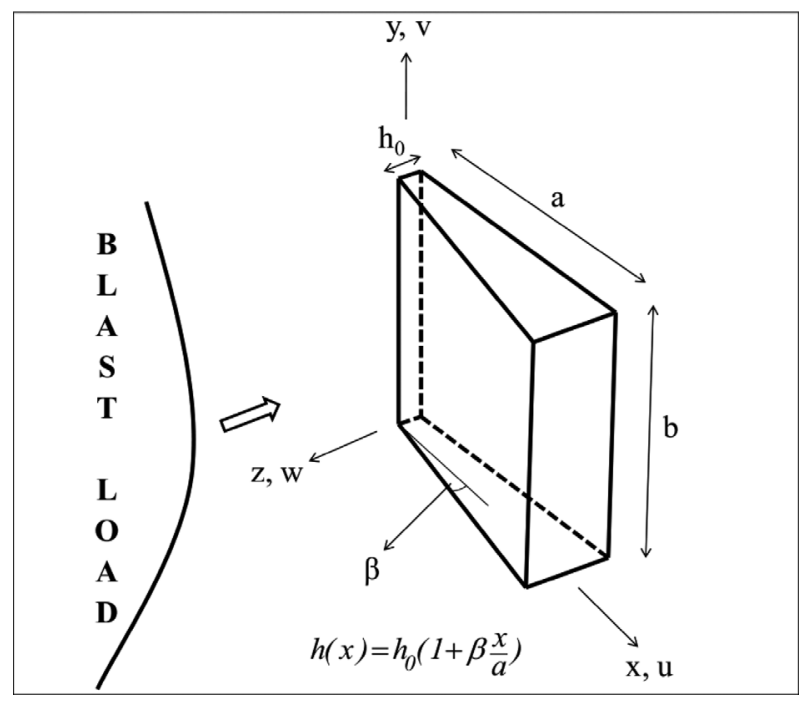

Fig. 1. The representation of the tapered plate subjected to blast loading.

The effect of the boundary conditions on the dynamic response of the elastic plates subjected to blast loading is also investigated [11]. In another study, the response of simply supported anti-symmetrically laminated angle-ply plates to explosive blast loading is considered [12]. A semi-analytical finite strip method is developed for the analysis of the nonlinear response to dynamic loading of simply supported rectangular laminated composite plates [13]. The results for nonlinear dynamic behaviour of a laminated composite plate subjected to blast loading are compared for different boundary conditions [14]. In another study, the dynamic response of laminated sandwich plates subjected to pressure pulses is investigated numerically [15]. In the papers mentioned above, only the flat plates are studied and the effect of several parameters such as boundary condition, load, stiffening, etc. on the dynamic response is investigated. The effect of tapering is also important and there are some studies reported on the vibration analysis of tapered plates [16-25]. However, there is not a study reported on the air blast loading of tapered laminated plates.

In this paper, a closed form solution is presented for the transient analysis of simply supported tapered laminated composite plates subjected to air blast loading. The geometric nonlinearity effects are taken into account using the von Kármán large deflection theory. In-plane stiffness and inertia effects are also taken into account in the formulation of the problem. The equations of motion for the plate are derived by the use of the virtual work principle [1,2]. The displacement-time and strain-time histories are obtained on certain points through the tapered direction. The results obtained by using the present method are compared with the ones obtained by using a commercial finite element code ANSYS. The effects of taper ratio, the stacking sequence and the fiber orientation angle on the dynamic response of the plate are also investigated.

\section{Equations of motions for tapered laminated plates}

In this section, a mathematical model for the tapered laminated composite plates subjected to air blast loading is presented. The rectangular tapered plate with the length $a$ and the width $b$ is depicted in Fig. 1. The thickness is varying in the $\mathrm{x}$ direction and denoted by $h(x)$. The taper ratio is defined by $\beta$ and the Cartesian axes are used in the derivation of the formulation.

The constitutive equations for a tapered laminated composite plate can be given as:

$$
\left\{\begin{array}{c}
N_{x} \\
N_{y} \\
N_{x y} \\
M_{x} \\
M_{y} \\
M_{x y}
\end{array}\right\}=\left[\begin{array}{llllll}
A_{11} & A_{12} & A_{16} & B_{11} & B_{12} & B_{16} \\
A_{12} & A_{22} & A_{26} & B_{12} & B_{22} & B_{26} \\
A_{16} & A_{26} & A_{66} & B_{16} & B_{26} & B_{66} \\
B_{11} & B_{12} & B_{16} & D_{11} & D_{12} & D_{16} \\
B_{12} & B_{22} & B_{26} & D_{12} & D_{22} & D_{26} \\
B_{16} & B_{26} & B_{66} & D_{16} & D_{26} & D_{66}
\end{array}\right]\left\{\begin{array}{c}
\varepsilon_{x}^{0} \\
\varepsilon_{y}^{0} \\
\varepsilon_{x y}^{0} \\
\kappa_{x} \\
\kappa_{y} \\
\kappa_{x y}
\end{array}\right\}
$$


where $M_{x}, M_{y}$, and $M_{x y}$ are moment components; $N_{x}, N_{y}$, and $N_{x y}$ are force components; $\varepsilon_{x}^{0}, \varepsilon_{y}^{0}$ and $\varepsilon_{x y}^{0}$ are the membrane strains and $\kappa_{x}, \kappa_{y}$ and $\kappa_{x y}$ are the curvatures and defined as:

$$
\begin{aligned}
\varepsilon_{x}^{0} & =\frac{\partial u^{0}}{\partial x}+\frac{1}{2}\left(\frac{\partial w^{0}}{\partial x}\right)^{2} \\
\varepsilon_{y}^{0} & =\frac{\partial v^{0}}{\partial y}+\frac{1}{2}\left(\frac{\partial w^{0}}{\partial y}\right)^{2} \\
\varepsilon_{x y}^{0} & =\frac{\partial u^{0}}{\partial y}+\frac{\partial v^{0}}{\partial x}+\frac{\partial w^{0}}{\partial x} \frac{\partial w^{0}}{\partial y} \\
\kappa_{x} & =-\frac{\partial^{2} w^{0}}{\partial x^{2}} \\
\kappa_{y} & =-\frac{\partial^{2} w^{0}}{\partial y^{2}} \\
\kappa_{x y} & =-2 \frac{\partial^{2} w^{0}}{\partial x \partial y}
\end{aligned}
$$

Here $u^{0}, v^{0}$, and $w^{0}$ are displacement components of reference surface in the $x, y$, and $z$ directions.

The coefficients shown in Eq. (1) are as follows:

$$
\begin{aligned}
& A_{i j}=\sum_{k=1}^{n}\left(\bar{Q}_{i j}\right)_{k}\left(h_{k}-h_{k-1}\right) \\
& B_{i j}=1 / 2 \sum_{k=1}^{n}\left(\bar{Q}_{i j}\right)_{k}\left(h_{k}^{2}-h_{k-1}^{2}\right) \\
& D_{i j}=1 / 3 \sum_{k=1}^{n}\left(\bar{Q}_{i j}\right)_{k}\left(h_{k}^{3}-h_{k-1}^{3}\right)
\end{aligned}
$$

Here, $\bar{Q}_{i j}$ 's are the reduced stiffness coefficients for a layer of the laminated composite [26].

Using the constitutive equations and the strain-displacement relations in the virtual work and applying the variational principles, nonlinear dynamic equations of a tapered laminated plate can be obtained in terms of mid-plane displacements as [1,2]:

$$
\begin{aligned}
& L_{11} u^{0}+L_{12} v^{0}+L_{13} w^{0}+N_{1}\left(w^{0}\right)+\bar{m} \ddot{u}^{0}-q_{x}=0 \\
& L_{21} u^{0}+L_{22} v^{0}+L_{23} w^{0}+N_{2}\left(w^{0}\right)+\bar{m} \ddot{v}^{0}-q_{y}=0 \\
& L_{31} u^{0}+L_{32} v^{0}+L_{33} w^{0}+N_{3}\left(u^{0}, v^{0}, w^{0}\right)+\bar{m} \ddot{w}^{0}-q_{z}=0
\end{aligned}
$$

where $L_{i j}$ and $N_{i}$ denote the linear and nonlinear operators, respectively. $\bar{m}$ is the mass of unit area of the mid-plane; $\ddot{u}^{0}, \ddot{v}^{0}$ and $\ddot{w}^{0}$ are the components of acceleration vector; $q_{x}, q_{y}$ and $q_{z}$ are the load vectors in the directions of coordinate axes. The explicit expressions of the operators $L_{i j}$ and $N_{i}$ are given in an Appendix and also can be found in Kazancı and Mecitoğlu [2]. The boundary conditions for a simply supported plate can be given in the following form:

$$
\begin{aligned}
& u^{0}(0, y, t)=u^{0}(a, y, t)=u^{0}(x, 0, t)=u^{0}(x, b, t)=0 \\
& v^{0}(0, y, t)=v^{0}(a, y, t)=v^{0}(x, 0, t)=v^{0}(x, b, t)=0 \\
& w^{0}(0, y, t)=w^{0}(a, y, t)=w^{0}(x, 0, t)=w^{0}(x, b, t)=0
\end{aligned}
$$



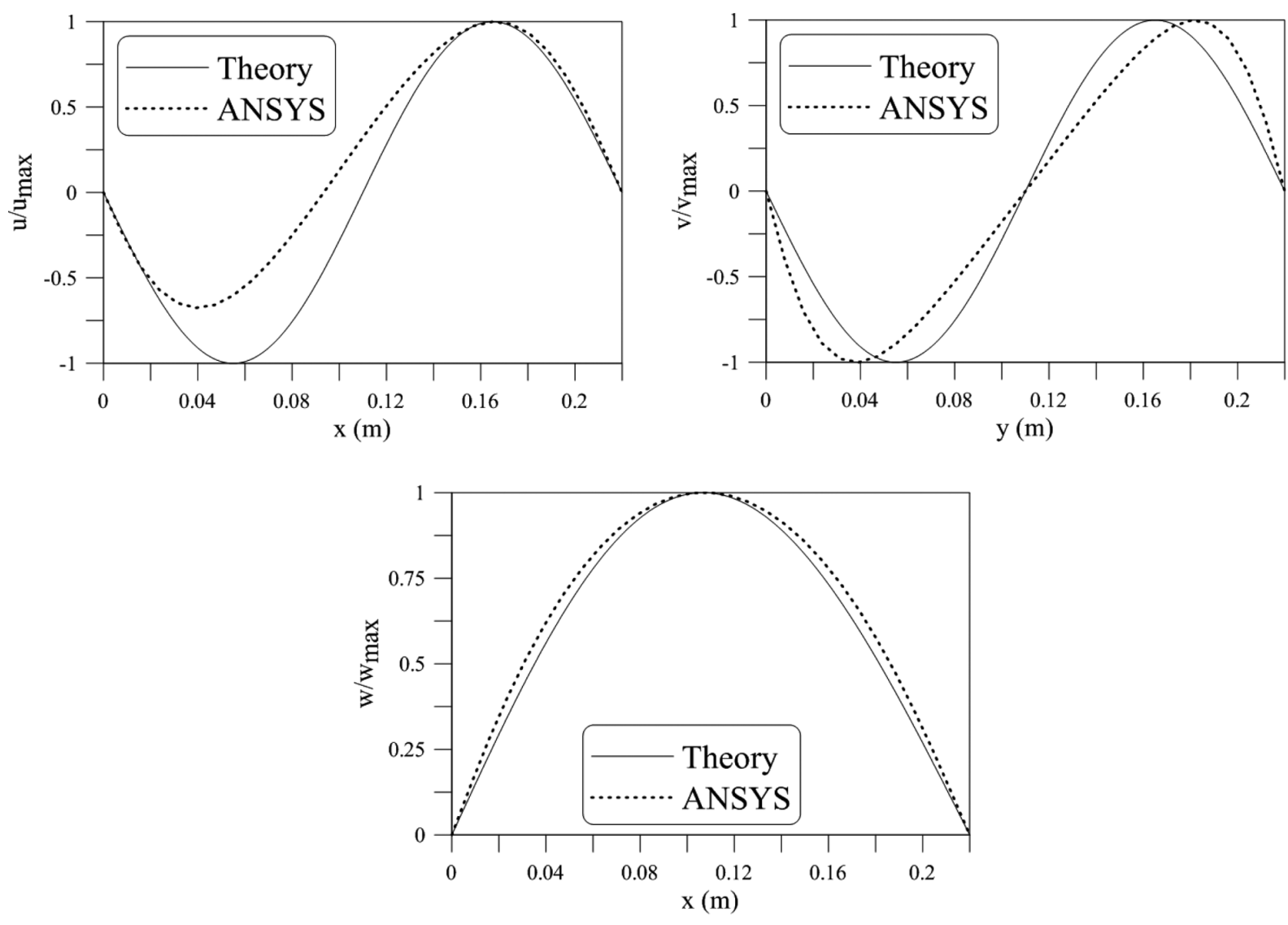

Fig. 2. Variation of $u(\mathrm{x}, \mathrm{b} / 2), v(\mathrm{a} / 2, \mathrm{y})$ and $w(\mathrm{x}, \mathrm{b} / 2)$.

$$
\begin{aligned}
& M_{x}=0 \text { at } x=0, a \\
& M_{y}=0 \text { at } y=0, b
\end{aligned}
$$

and initial conditions are given as:

$$
\begin{aligned}
& u^{0}(x, y, 0)=0, v^{0}(x, y, 0)=0, w^{0}(x, y, 0)=0 \\
& \dot{u}^{0}(x, y, 0)=0, \dot{v}^{0}(x, y, 0)=0, \dot{w}^{0}(x, y, 0)=0
\end{aligned}
$$

Here, $\dot{u}^{0}, \dot{v}^{0}$ and $\dot{w}^{0}$ are the components of velocity vector. The plate is subjected to the blast load in the $z$ direction. Therefore, $q_{x}=q_{y}=0$, and $q_{z}$ is expanded in Fourier series and only the first term is chosen. The blast load is assumed to be varying exponentially in time and Friedlander decay function is used to express the air blast load as shown below:

$$
p(x, y, t)=p_{m}\left(1-t / t_{p}\right) e^{-\alpha t / t_{p}}
$$

Here, $p_{m}$ is the peak pressure, $t_{p}$ is positive phase duration, and $\alpha$ is a waveform parameter.

\section{Method of solution}

\subsection{Closed form solution}

The equations of motion can be reduced into time domain by choosing proper approximation functions for displacement field and applying the Galerkin method. The approximation functions are determined by considering 
the results of static large deformation analysis of laminated tapered plate with $\beta=1.2$ under the uniform pressure load by using ANSYS. The variations of $u(x, b / 2), v(a / 2, y)$, and $w(x, b / 2)$ obtained from ANSYS and solution functions considered here are compared and this comparison is shown in Fig. 2. It is found that the solution function chosen for $w$ agreed well with the static analysis result although small discrepancies occurred for the solution functions chosen for $u$ and $v$. Approximate solution functions which are chosen considering only the first term of the series for in-plane displacements and the first two terms of the series for out-of-plane displacements for the simply supported tapered plate are shown below:

$$
\begin{aligned}
u^{0} & =U(t) \sin \frac{2 \pi x}{a} y^{2}(y-b)^{2} \\
v^{0} & =V(t) x^{2}(x-a)^{2} \sin \frac{2 \pi y}{b} \\
w^{0} & =W_{1}(t) \sin \frac{\pi x}{a} \sin \frac{\pi y}{b}+W_{2}(t) \sin \frac{2 \pi x}{a} \sin \frac{\pi y}{b}
\end{aligned}
$$

Here $U, V, W_{1}$ and $W_{2}$ are time dependent parts of displacement components. By using the approximation functions in Eq. (4), the coupled-nonlinear algebraic differential equations in time domain are obtained as follows:

$$
\begin{aligned}
& a_{0} \ddot{U}+a_{1} U+a_{2} V+a_{3} W_{1}^{2}+a_{4} W_{1} W_{2}+a_{5}=0 \\
& b_{0} \ddot{V}+b_{1} V+b_{2} U+b_{3} W_{1}^{2}+b_{4} W_{2}^{2}+b_{5} W_{1} W_{2}+b_{6}=0 \\
& c_{0} \ddot{W}_{1}+c_{1} W_{1}+c_{2} W_{1}^{3}+c_{3} W_{2}+c_{4} W_{2}^{3}+c_{5} U W_{1}+c_{6} V W_{1}+c_{7} U W_{2}+c_{8} V W_{2}+c_{9} W_{1} W_{2}^{2} \\
& \quad+c_{10} W_{2} W_{1}^{2}+c_{11}=0 \\
& d_{0} \ddot{W}_{2}+d_{1} W_{2}+d_{2} W_{2}^{3}+d_{3} W_{1}+d_{4} W_{1}^{3}+d_{5} V W_{2}+d_{6} U W_{1}+d_{7} V W_{1}+d_{8} W_{2} W_{1}^{2} \\
& \quad+d_{9} W_{1} W_{2}^{2}+d_{10}=0
\end{aligned}
$$

The coefficients shown in Eq. (9) are given in an Appendix. The initial conditions can be expressed as:

$$
\begin{array}{llll}
U(0)=0, & V(0)=0, & W_{1}(0)=0, & W_{2}(0)=0 \\
\dot{U}(0)=0, & \dot{V}(0)=0, & \dot{W}_{1}(0)=0, & \dot{W}_{2}(0)=0
\end{array}
$$

The nonlinear-coupled equations of motion are solved by using the finite difference method. For this purpose, Eq. (9) are arranged in the matrix format as:

$$
[M]\{\ddot{Q}\}+\left[K_{L}\right]\{Q\}+\left[K_{N L}\right]\{Q\}+[F]=\{0\}
$$

where $\{Q\}=\left\{\begin{array}{lll}U V & W_{1} & W_{2}\end{array}\right\}^{T}$ and $\{\ddot{Q}\}=\left\{\begin{array}{llll}\ddot{U} & \ddot{V} & \ddot{W}_{1} & \ddot{W}_{2}\end{array}\right\}^{T}$ denote the displacement and acceleration vectors, respectively. In Eq. (11), $[M],\left[K_{L}\right]$, and $\left[K_{N L}\right]$ matrices are given as:

$$
\begin{aligned}
{[M]=} & {\left[\begin{array}{cccc}
a_{0} & 0 & 0 & 0 \\
0 & b_{0} & 0 & 0 \\
0 & 0 & c_{0} & 0 \\
0 & 0 & 0 & d_{0}
\end{array}\right] } \\
{\left[K_{L}\right]=} & {\left[\begin{array}{cccc}
a_{1} & a_{2} & 0 & 0 \\
b_{2} & b_{1} & 0 & 0 \\
0 & 0 & c_{1} & c_{3} \\
0 & 0 & d_{3} & d_{1}
\end{array}\right] } \\
{\left[K_{N L}\right] } & =\left[\begin{array}{cccc} 
\\
c_{5} W_{1}+c_{7} W_{2} & c_{6} W_{1}+c_{8} W_{2} & c_{2} W_{1}^{2}+c_{9} W_{2}^{2} & c_{4} W_{2}^{2}+c_{10} W_{1}^{2} \\
d_{6} W_{1} & d_{7} W_{1}+d_{5} W_{2} & d_{4} W_{1}^{2}+d_{9} W_{2}^{2} & d_{2} W_{2}^{2}+d_{8} W_{1}^{2}
\end{array}\right]
\end{aligned}
$$


and $[F]$ vector is given as:

$$
\{F\}=\left\{\begin{array}{llll}
a_{5} & b_{6} & c_{11} & d_{10}
\end{array}\right\}^{T}
$$

If we replace the $\frac{\partial^{2}}{\partial t^{2}}\{Q\}$ term with $\frac{\partial}{\partial t}\{\dot{Q}\}$ in Eq. (11), we can write the Eq. (11) as:

$$
[M] \frac{\partial}{\partial t}\{\dot{Q}\}+[K]\{Q\}+\{F\}=\{0\}
$$

where $[K]=\left[K_{L}\right]+\left[K_{N L}\right]$.

Using the definition of derivation, the Eq. (13) can be written as:

$$
[M] \frac{\{\dot{Q}\}^{n+1}-\{\dot{Q}\}^{n}}{\Delta t}+[K]\{Q\}^{n+1}+\{F\}=\{0\}
$$

Substituting $\{\dot{Q}\}^{n+1}=\frac{\{Q\}^{n+1}-\{Q\}^{n}}{\Delta t}$ in Eq. (14) and rearranging it, we obtain the following equation:

$$
\left(\frac{1}{(\Delta t)^{2}}[M]+[K]\right)\{Q\}^{n+1}=\frac{1}{\Delta t}[M]\{\dot{Q}\}^{n}+\left(\frac{1}{(\Delta t)^{2}}[M]\right)\{Q\}^{n}-\{F\}
$$

Finally, if the matrices and vector given in Eq. (12) are substituted into the Eq. (15), the equations of motion are reduced into the following form:

$$
\begin{aligned}
A_{1} U^{n+1}+A_{2} V^{n+1}+A_{3} W_{1}^{n+1}+A_{4} W_{2}^{n+1} & =A_{5} \\
B_{1} U^{n+1}+B_{2} V^{n+1}+B_{3} W_{1}^{n+1}+B_{4} W_{2}^{n+1} & =B_{5} \\
C_{1} U^{n+1}+C_{2} V^{n+1}+C_{3} W_{1}^{n+1}+C_{4} W_{2}^{n+1} & =C_{5} \\
D_{1} U^{n+1}+D_{2} V^{n+1}+D_{3} W_{1}^{n+1}+D_{4} W_{2}^{n+1} & =D_{5}
\end{aligned}
$$

The coefficients in the equations are given in the Appendix. From Eq. (16), the following expressions are obtained by using Gauss elimination method and the resulting Eq. (17) are solved by iterations.

$$
\begin{aligned}
U^{n+1} & =\frac{1}{A_{1}}\left[A_{5}-A_{2} V^{n+1}-A_{3} W_{1}^{n+1}-A_{4} W_{2}^{n+1}\right] \\
V^{n+1} & =E_{1}+E_{2} W_{1}^{n+1}+E_{3} W_{2}^{n+1} \\
W_{1}^{n+1} & =F_{1}+F_{2} W_{2}^{n+1} \\
W_{2}^{n+1} & =\frac{G_{2}}{G_{1}}
\end{aligned}
$$

\subsection{Finite element solution}

The simply supported tapered laminated plate is modeled using ANSYS finite element software. The plate is discretized using $14 \times 14$ eight nodded layered shell elements (Shell281) which have the geometric nonlinearity capability. The individual laminas are assumed to be perfectly bonded in the finite element model. The number of elements is chosen as $14 \times 14$ based on the mesh sensitivity analysis. The details of the mesh sensitivity analysis are given in the following section. A function is used to describe the variation of the thickness. The finite element model is constructed for each taper ratio considered in this study and for the flat plate separately. The air blast loading, given in Eq. (7), is applied on the plate. The transient analyses are performed to obtain the displacement-time and strain-time histories at certain points through the tapered direction. The finite element model of the plate is shown in Fig. 3a and the cross-section of the regarding plate is also shown in Fig. $3 \mathrm{~b}$ which illustrates the variation of thickness along the $x$-axis. 
Table 1

Material properties of laminae [27]

\begin{tabular}{lccc}
\hline & $\begin{array}{c}\text { E7781/EA9396 } \\
\text { Bidirectional } \\
\text { Glass (BG) }\end{array}$ & $\begin{array}{c}\text { T-300 15k/976 } \\
\text { Unidirectional } \\
\text { Carbon (UC) }\end{array}$ & $\begin{array}{c}\text { T300 3k/EA9396 } \\
\text { Bidirectional } \\
\text { Carbon (BC) }\end{array}$ \\
\hline$E_{1}(\mathrm{GPa})$ & 23.37 & 135.14 & 62.74 \\
$E_{2}(\mathrm{GPa})$ & 23.37 & 9.24 & 62.74 \\
$\nu_{12}$ & 0.115 & 0.318 & 0.059 \\
$G_{12}(\mathrm{GPa})$ & 5.23 & 6.27 & 4.37 \\
$\rho\left(\mathrm{kg} / \mathrm{m}^{3}\right)$ & 1910 & 1620 & 1450 \\
\hline
\end{tabular}

Table 2

The positive and negative peak values of central displacements for $[\mathrm{BCUCBG}]_{s}$ plate with $\beta=1.2$ for different mesh sizes (mm)

\begin{tabular}{|c|c|}
\hline Mesh size & {$[\mathrm{BCUCBG}]_{s}$} \\
\hline $6 \times 6$ & $\begin{array}{r}3.24 \\
-3.60\end{array}$ \\
\hline $14 \times 14$ & $\begin{array}{r}3.42 \\
-3.84\end{array}$ \\
\hline $28 \times 28$ & $\begin{array}{r}3.46 \\
-3.79\end{array}$ \\
\hline $56 \times 56$ & $\begin{array}{r}3.46 \\
-3.79\end{array}$ \\
\hline
\end{tabular}

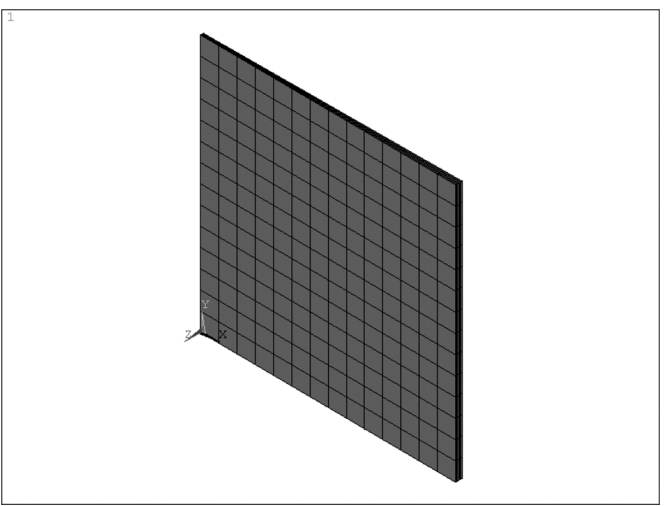

(a)

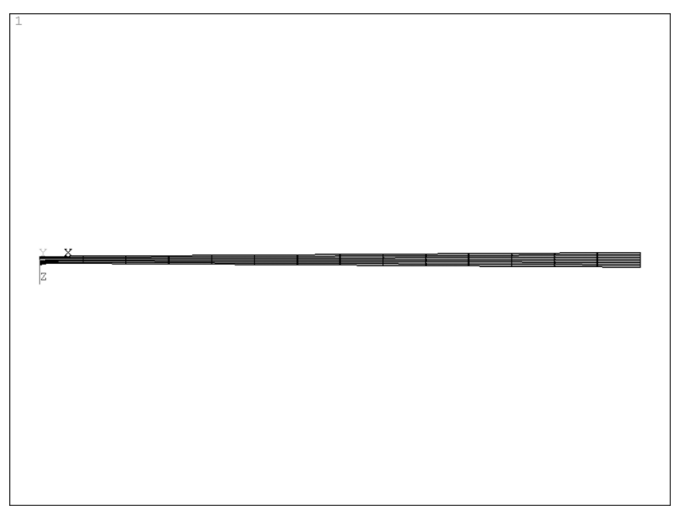

(b)

Fig. 3. (a) Finite element model of the tapered laminated plate. (b) Cross section of the tapered laminated plate.

\section{Numerical results}

The dynamic behaviour of tapered laminated composite plates is obtained using the closed form solution and FEM. The pressure distribution because of the blast loading Eq. (7), $p$, is assumed to be uniform on the plate, and the parameters shown in Eq. (7) are $p_{m}=28906 \mathrm{~N} / \mathrm{m}^{2}, t_{p}=0.0018 \mathrm{~s}, \alpha=0.35$. Only square shaped plates are considered in this paper and the dimensions are taken as $a=b=220 \mathrm{~mm}$. The plates are made of the symmetrically placed six layers of laminae, which are assumed to be behaving linearly and elastically. Mechanical and physical properties and the abbreviation of each lamina are shown in Table 1 [27]. Here, $E_{1}$ and $E_{2}$ are Young's modulus, $G_{12}$ is shear modulus, $\nu_{12}$ is Poisson's ratio, and $\rho$ is defined as the density of the material. The three different laminae are considered to understand the effect of the stacking sequence on the dynamic behaviour. The taper ratios are chosen as $\beta=0$ (flat plate), $\beta=0.2, \beta=0.7$ and $\beta=1.2$ for [UCBGBC] $]_{s}$ laminate to understand the effect of taper ratio on the dynamic response. The plate thickness is taken as $2 \mathrm{~mm}$ at the center of the plate for all configurations so that the weight of the plate is kept constant. The minimum thickness $h_{0}$ can be calculated from the equation which shows the variation of the thickness stated in Fig. 1. 


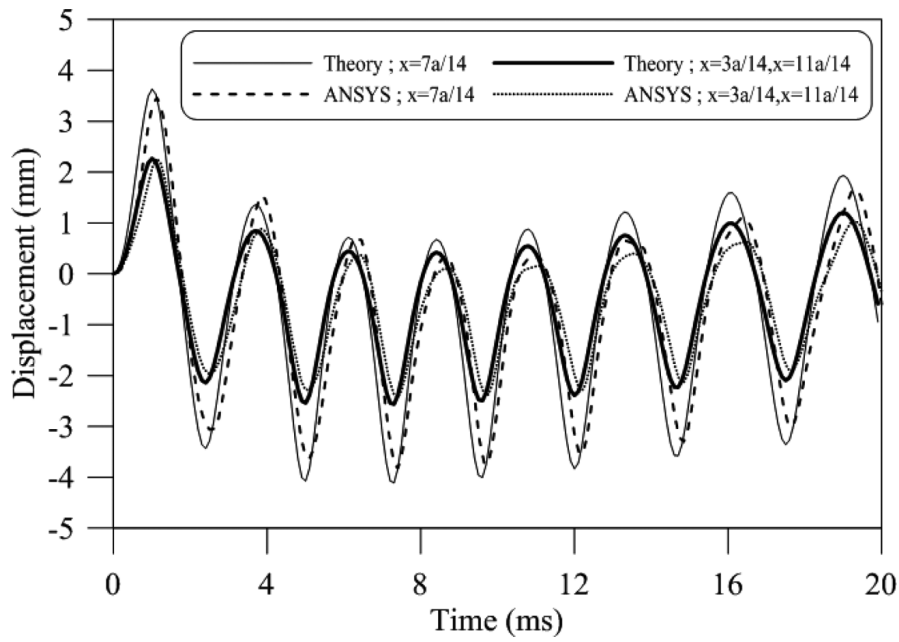

Fig. 4. The displacement-time histories of the simply-supported laminated flat plates $(\beta=0)$.

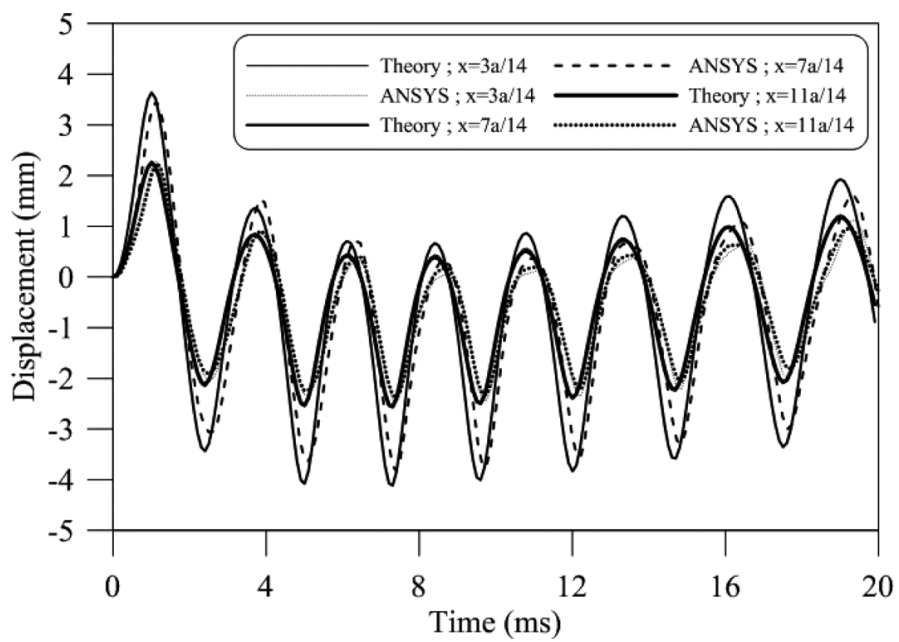

Fig. 5. The displacement-time histories of the simply-supported tapered laminated plates $(\beta=0.2)$.

A convergence study is carried out to check the mesh sensitivity on the results before deciding the mesh size. For this purpose, the plate is discretized by using $6 \times 6,14 \times 14,28 \times 28$ and $56 \times 56$ elements, respectively. The displacement-time histories of the point $\mathrm{x}=7 a / 14$ through the center line of the plate is obtained in each case for $[\mathrm{BCUCBG}]_{s}$ plate with a taper ratio of $\beta=1.2$. The positive and negative maximum deflections are given in Table 2 for each case. It is decided that the sufficient accuracy is obtained by using $14 \times 14$ elements. The displacement-time histories of the points $\mathrm{x}=3 a / 14, \mathrm{x}=7 a / 14$ and $\mathrm{x}=11 a / 14$ through the center line of the plate $(\mathrm{y}=b / 2)$ are obtained using both present method and FEM for $[\mathrm{UCBGBC}]_{s}$ plate for all taper ratios considered in this study. The results presented in Figs 4-18 are obtained for the fiber orientation angle of $0^{\circ}$ for all layers. The displacement-time histories of the simply-supported flat laminated plates are shown in Fig. 4. The displacement-time histories of the selected points through the central axis obtained by using closed form solution are found to be in an agreement with the FEM results. The displacement-time histories of the simply-supported tapered laminated plates with a taper ratio of $0.2,0.7$ and 1.2 are shown in Figs 5-7, respectively. The displacement-time histories of the selected points through the central axis obtained by using closed form solution are found to be in an agreement with the FEM results.

The strain-time histories of the points $\mathrm{x}=a / 14, \mathrm{x}=7 a / 14$ and $\mathrm{x}=11 a / 14$ through the center line of the plate (y 


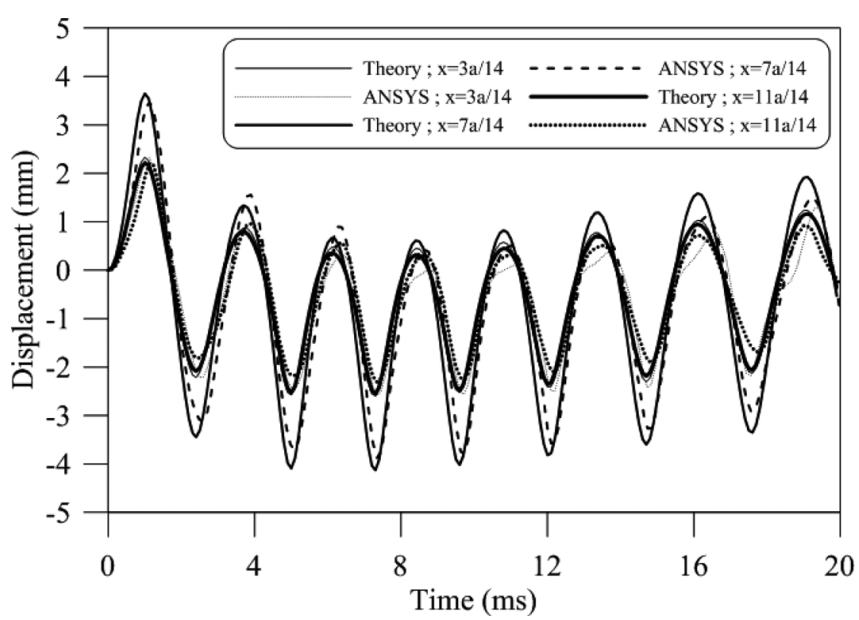

Fig. 6. The displacement-time histories of the simply-supported tapered laminated plates $(\beta=0.7)$.

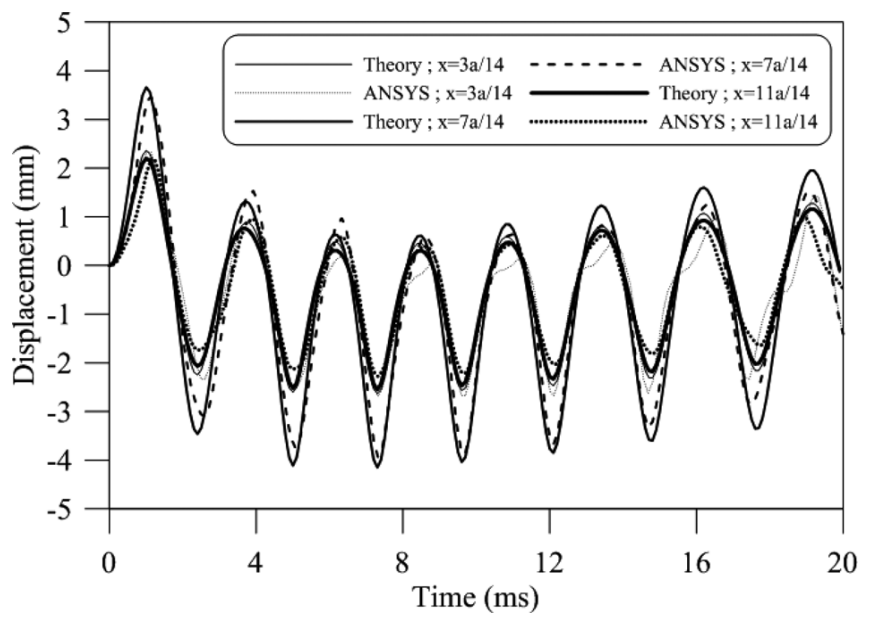

Fig. 7. The displacement-time histories of the simply-supported tapered laminated plates $(\beta=1.2)$.

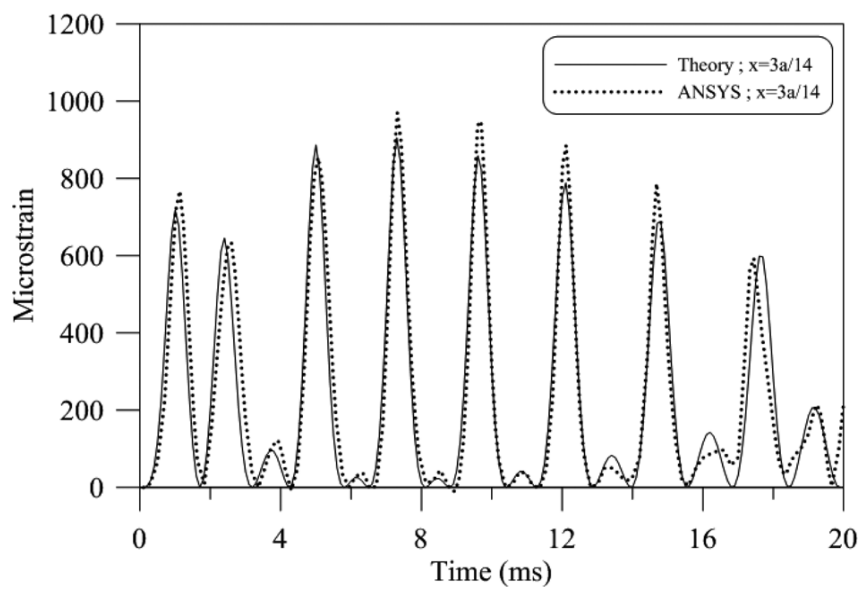

Fig. 8. The strain-time history $\left(\varepsilon_{x m}-t\right)$ at the middle surface of point $(3 \mathrm{a} / 14, \mathrm{~b} / 2)$. 


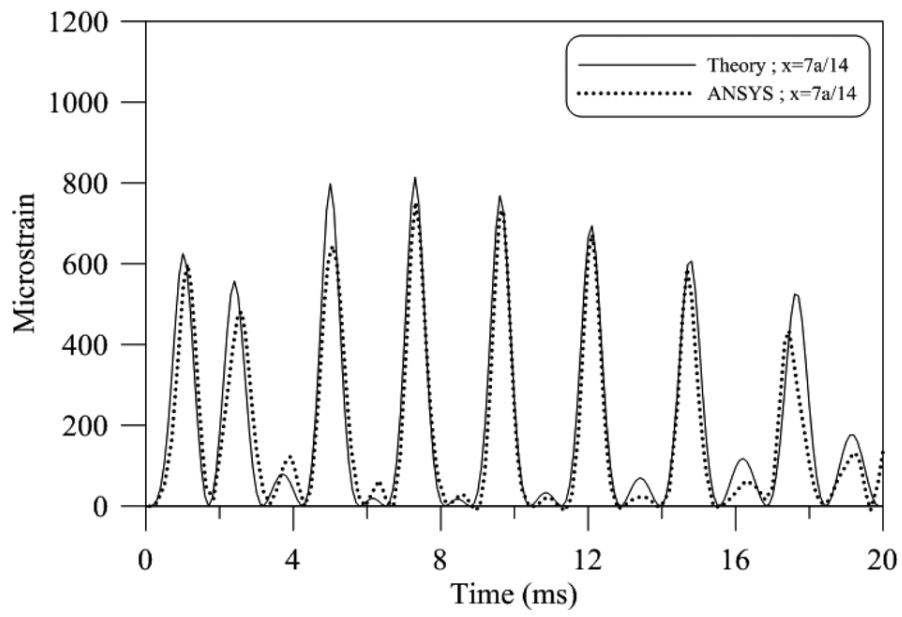

Fig. 9. The strain-time history $\left(\varepsilon_{x m}-t\right)$ at middle surface of point $(7 \mathrm{a} / 14, \mathrm{~b} / 2)$.

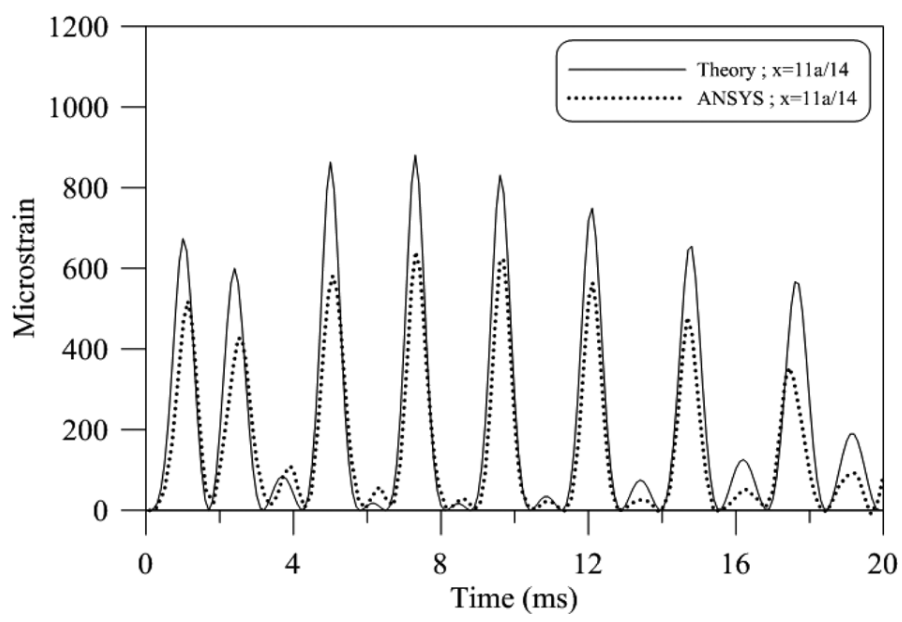

Fig. 10. The strain-time history $\left(\varepsilon_{x m}-t\right)$ at middle surface of point $(11 \mathrm{a} / 14, \mathrm{~b} / 2)$.

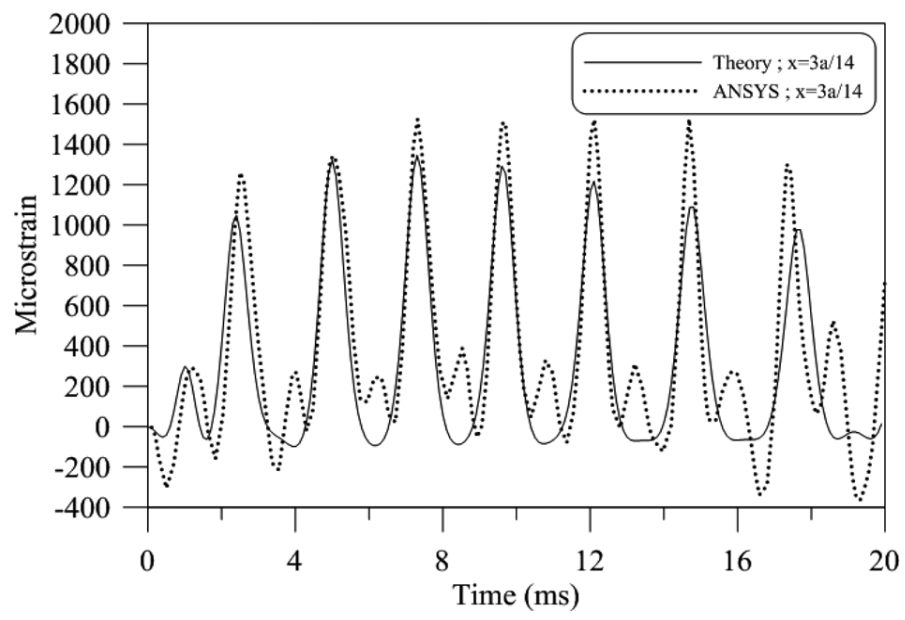

Fig. 11. The strain-time history $\left(\varepsilon_{x b}-t\right)$ at bottom surface of point $(3 \mathrm{a} / 14, \mathrm{~b} / 2)$. 
Table 3

The positive and negative peak values of displacements for $\beta=1.2(\mathrm{~mm})$

\begin{tabular}{|c|c|c|c|c|c|c|c|c|c|}
\hline \multirow[b]{2}{*}{$x$} & \multicolumn{3}{|c|}{$[\mathrm{UCBGBC}]_{s}$} & \multicolumn{3}{|c|}{$[\mathrm{BGUCBC}]_{s}$} & \multicolumn{3}{|c|}{$[\mathrm{BCUCBG}]_{s}$} \\
\hline & $3 a / 14$ & $7 \mathrm{a} / 14$ & $11 \mathrm{a} / 14$ & $3 a / 14$ & $7 a / 14$ & $11 \mathrm{a} / 14$ & $3 a / 14$ & $7 \mathrm{a} / 14$ & $11 \mathrm{a} / 14$ \\
\hline \multirow[t]{2}{*}{ Theory } & 2.36 & 3.66 & 2.19 & 2.43 & 3.76 & 2.25 & 2.36 & 3.64 & 2.18 \\
\hline & -2.63 & -4.15 & -2.54 & -2.76 & -4.17 & -2.51 & -2.61 & -4.07 & -2.48 \\
\hline \multirow[t]{2}{*}{ ANSYS } & 2.33 & 3.47 & 2.18 & 2.33 & 3.62 & 2.26 & 2.35 & 3.42 & 2.12 \\
\hline & -2.68 & -3.93 & -2.28 & -2.75 & -3.94 & -2.49 & -2.81 & -3.84 & -2.45 \\
\hline
\end{tabular}

Table 4

Peak values of displacements and strains for different taper ratios and [UCBGBC] $s$ plate

\begin{tabular}{|c|c|c|c|c|c|}
\hline & & $x$ & $\beta=0.2$ & $\beta=0.7$ & $\beta=1.2$ \\
\hline \multirow[t]{6}{*}{$w(\mathrm{~mm})$} & \multirow[t]{3}{*}{ Theory } & $3 a / 14$ & $2.29 /-2.57$ & $2.33 /-2.6$ & $2.36 /-2.63$ \\
\hline & & $7 \mathrm{a} / 14$ & $3.64 /-4.11$ & $3.65 /-4.13$ & $3.66 /-4.15$ \\
\hline & & $11 \mathrm{a} / 14$ & $2.25 /-2.56$ & $2.22 /-2.55$ & $2.19 /-2.54$ \\
\hline & \multirow[t]{3}{*}{ ANSYS } & $3 a / 14$ & $2.29 /-2.48$ & $2.32 /-2.59$ & $2.33 /-2.68$ \\
\hline & & $7 \mathrm{a} / 14$ & $3.46 /-3.83$ & $3.47 /-3.87$ & $3.47 /-3.93$ \\
\hline & & $11 \mathrm{a} / 14$ & $2.24 /-2.38$ & $2.2 /-2.31$ & $2.18 /-2.28$ \\
\hline \multirow[t]{6}{*}{$\varepsilon_{x m}($ microstrain $)$} & \multirow[t]{3}{*}{ Theory } & $3 a / 14$ & 876.31 & 889.05 & 905.75 \\
\hline & & $7 \mathrm{a} / 14$ & 807.8 & 811.73 & 815.01 \\
\hline & & $11 \mathrm{a} / 14$ & 872.7 & 876.18 & 881.3 \\
\hline & \multirow[t]{3}{*}{ ANSYS } & $3 a / 14$ & 800.68 & 891 & 970.14 \\
\hline & & $7 \mathrm{a} / 14$ & 740.56 & 747.04 & 752.7 \\
\hline & & $11 \mathrm{a} / 14$ & 725.52 & 674.11 & 641.7 \\
\hline \multirow[t]{6}{*}{$\varepsilon_{x b}($ microstrain $)$} & \multirow[t]{3}{*}{ Theory } & $3 a / 14$ & 1376.72 & 1351.25 & 1346.5 \\
\hline & & $7 \mathrm{a} / 14$ & 1646.48 & 1653.97 & 1661.78 \\
\hline & & $11 \mathrm{a} / 14$ & 1417.6 & 1459.01 & 1482.24 \\
\hline & \multirow[t]{3}{*}{ ANSYS } & $3 a / 14$ & 1350.01 & 1445.77 & 1526.6 \\
\hline & & $7 \mathrm{a} / 14$ & 1488.74 & 1512.53 & 1532.18 \\
\hline & & $11 \mathrm{a} / 14$ & 1247.17 & 1145.21 & 1089.02 \\
\hline \multirow[t]{6}{*}{$\varepsilon_{x t}($ microstrain $)$} & \multirow[t]{3}{*}{ Theory } & $3 \mathrm{a} / 14$ & 1143.84 & 1139.23 & 1136.3 \\
\hline & & $7 \mathrm{a} / 14$ & 1373.63 & 1372.75 & 1371.79 \\
\hline & & $11 \mathrm{a} / 14$ & 1148.98 & 1153.96 & 1157.74 \\
\hline & \multirow[t]{3}{*}{ ANSYS } & $3 a / 14$ & 1238.3 & 1253 & 1245.39 \\
\hline & & $7 \mathrm{a} / 14$ & 1235.63 & 1235.3 & 1234.23 \\
\hline & & $11 \mathrm{a} / 14$ & 1197.86 & 1145.8 & 1145.46 \\
\hline
\end{tabular}

$=b / 2$ ) are obtained using both present method and FEM for [UCBGBC] $]_{s}$ plate with a taper ratio of $\beta=1.2$. The strain-time histories of the simply supported tapered laminated plate at the middle $\left(\varepsilon_{x m}-t\right)$, bottom $\left(\varepsilon_{x b}-t\right)$ and top $\left(\varepsilon_{x t}-t\right)$ surface of selected points are shown in from Figs 8 to 16. The membrane strains $\left(\varepsilon_{x m}\right)$ shown in from Figs 8 to 10 are always positive as expected. It is found that there is an agreement between the strain-time histories obtained by using closed form solution and FEM. A slight difference occurs between the closed form solution and FEM for the point of $x=11 a / 14$. This difference is because of the solution function chosen to define the deformation in closed form solution. In this study, in-plane deformations are described by using only the first term of the series solution while the out-of-plane deformation is described by using the first two terms of the series. The increase in the number of terms may improve the results, however it also increases the number of equations and makes the analysis more complex.

In addition to $[\mathrm{UCBGBC}]_{s}$ plate, two more configurations are analyzed for a taper ratio of $\beta=1.2$ to understand the effect of stacking sequence on the dynamic response of the plate. The displacement-time histories of the simplysupported tapered laminated plates with a taper ratio of 1.2 for different stacking sequences are shown in Figs 17 and 18. The displacement-time histories of the selected points through the central axis obtained by using closed form solution are found to be in an agreement with the FEM results. The positive and negative peak values of displacements during the first twenty seconds are recorded and given in Table 3. The peak values obtained by using both methods are found to be in an agreement. The maximum discrepancy of approximately ten percent occurs for the negative peak value of [UCBGBC] $s$ plate at the point of $x=11 a / 14$. The minimum deflection is obtained for $[\mathrm{BCUCBG}]_{s}$ plate. Furthermore, the positive and negative peak values of displacements and positive peak values of strains are also computed and given in Table 4 for $[\mathrm{UCBGBC}]_{s}$ plate and for all taper ratios considered in this study. 


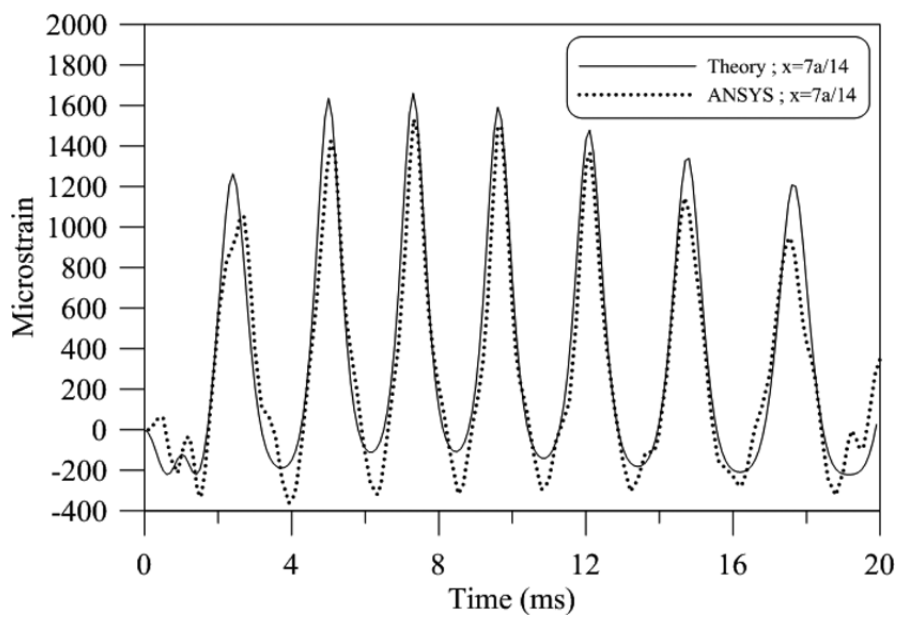

Fig. 12. The strain-time history $\left(\varepsilon_{x b}-t\right)$ at bottom surface of point $(7 \mathrm{a} / 14, \mathrm{~b} / 2)$.

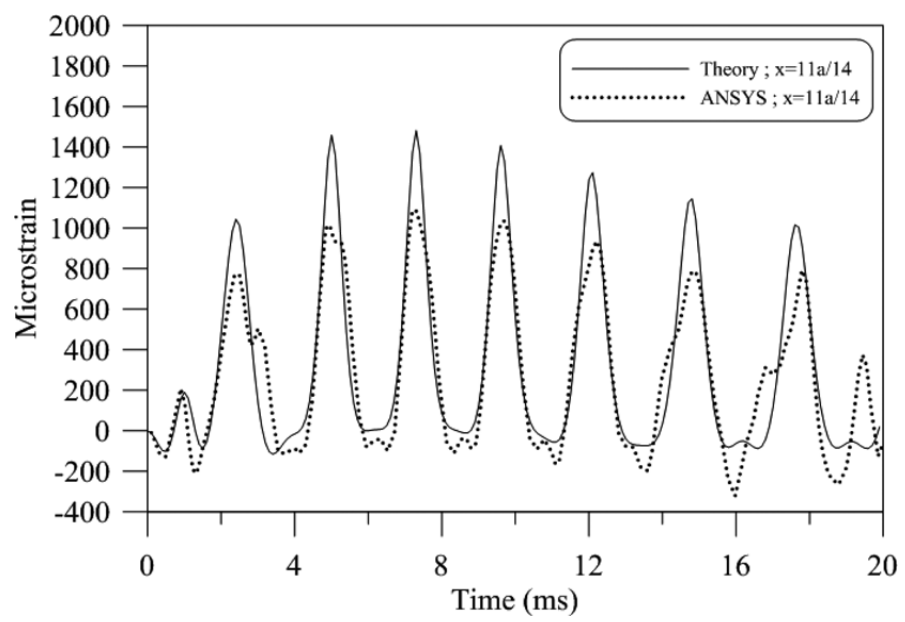

Fig. 13. The strain-time history $\left(\varepsilon_{x b}-t\right)$ at bottom surface of point $(11 \mathrm{a} / 14, \mathrm{~b} / 2)$.

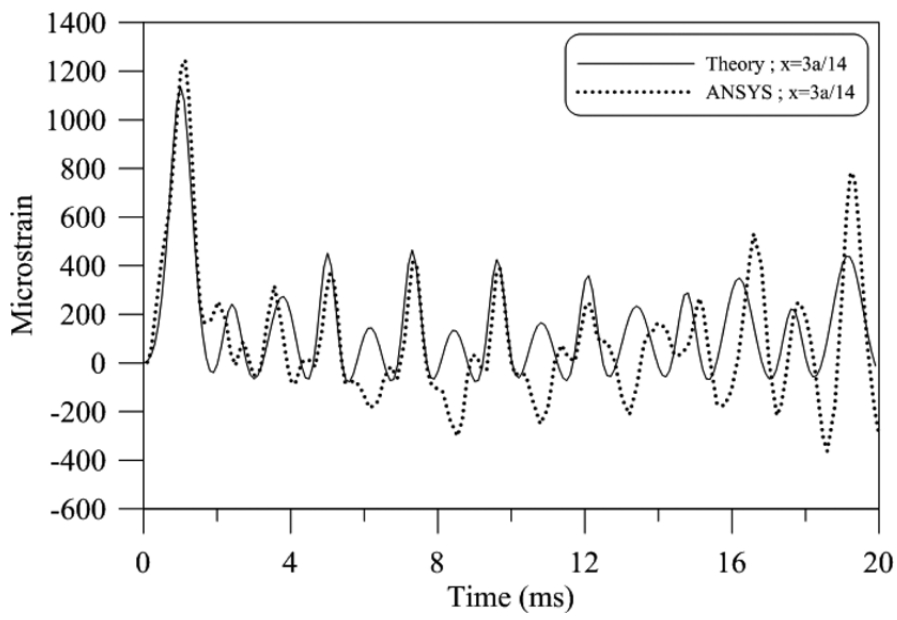

Fig. 14. The strain-time history $\left(\varepsilon_{x t}-t\right)$ at top surface of point $(3 \mathrm{a} / 14, \mathrm{~b} / 2)$. 


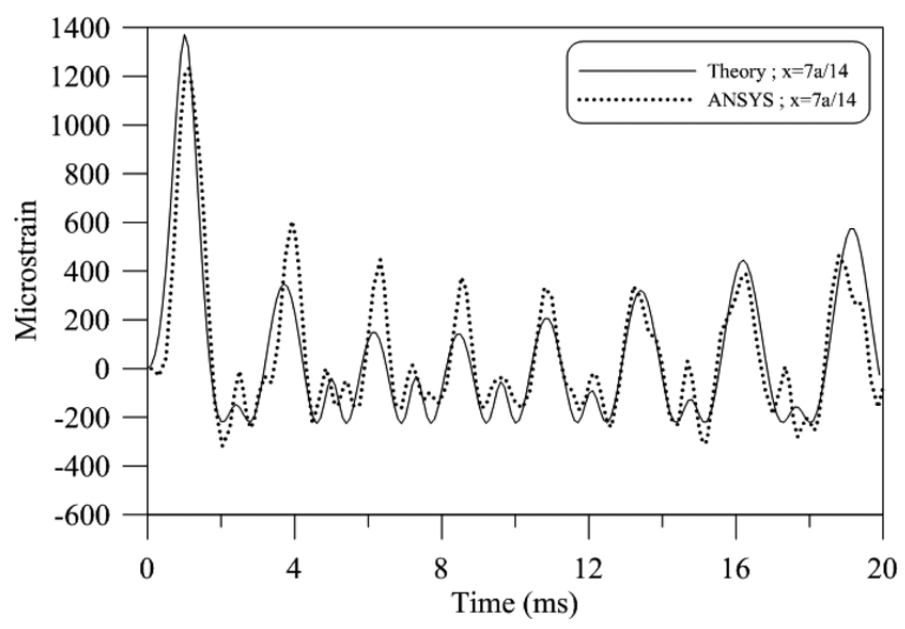

Fig. 15. The strain-time history $\left(\varepsilon_{x t}-t\right)$ at top surface of point $(7 \mathrm{a} / 14, \mathrm{~b} / 2)$.

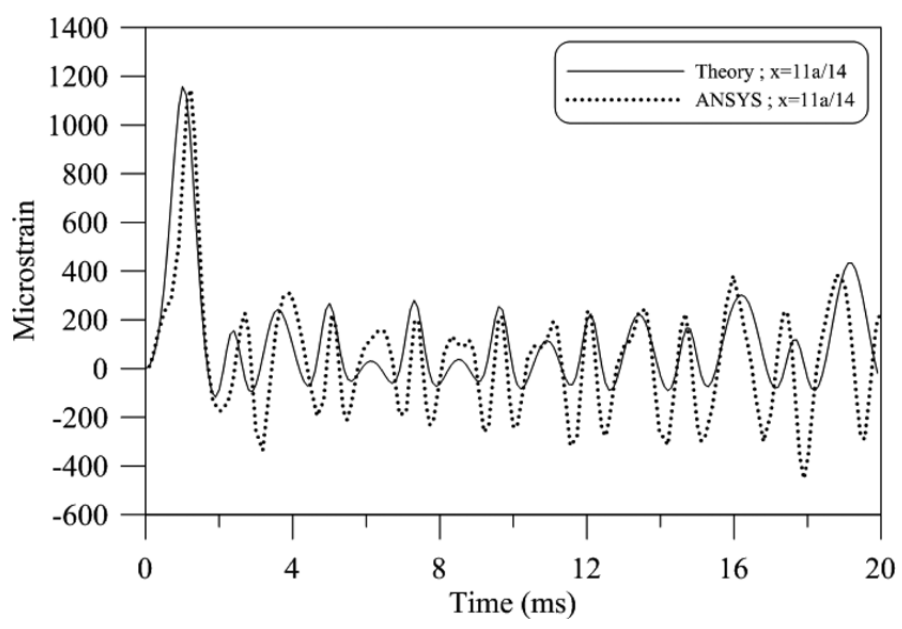

Fig. 16. The strain-time history $\left(\varepsilon_{x t}-t\right)$ at top surface of point $(11 \mathrm{a} / 14, \mathrm{~b} / 2)$.

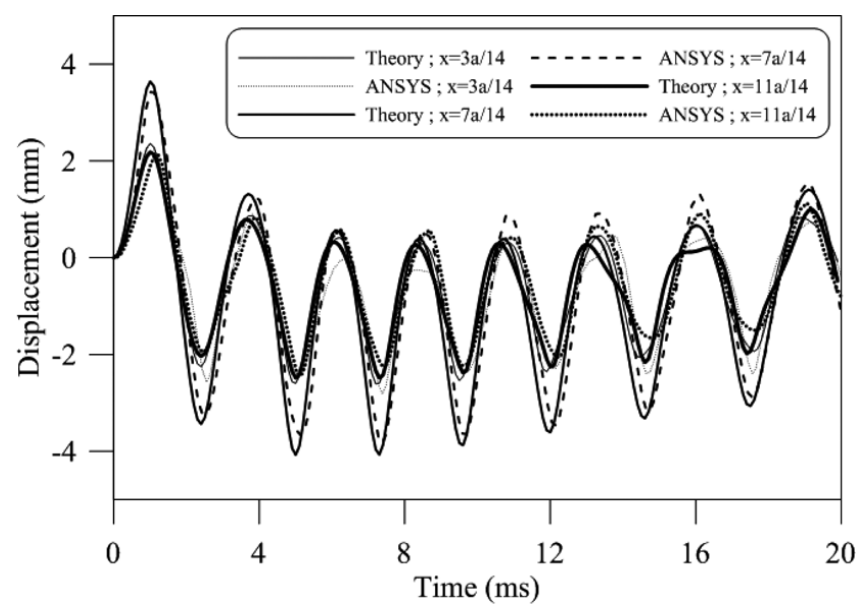

Fig. 17. The displacement-time histories of the simply-supported tapered laminated plates $(\beta=1.2)$ with $[0 / 0 / 0]_{S}$ for the stacking sequence $[\mathrm{BCUCBG}]_{S}$. 


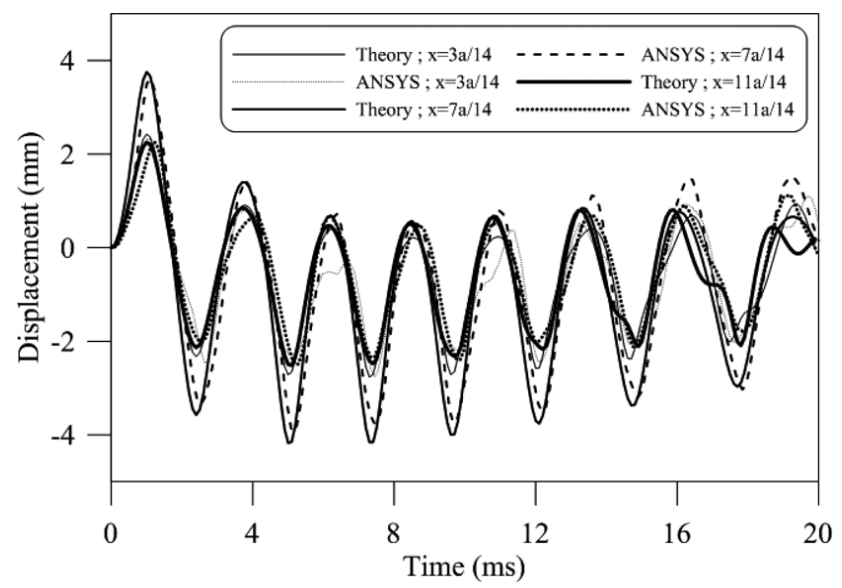

Fig. 18. The displacement-time histories of the simply-supported tapered laminated plates $(\beta=1.2)$ with $[0 / 0 / 0]_{S}$ for the stacking sequence $[\mathrm{BGUCBC}]_{S}$.

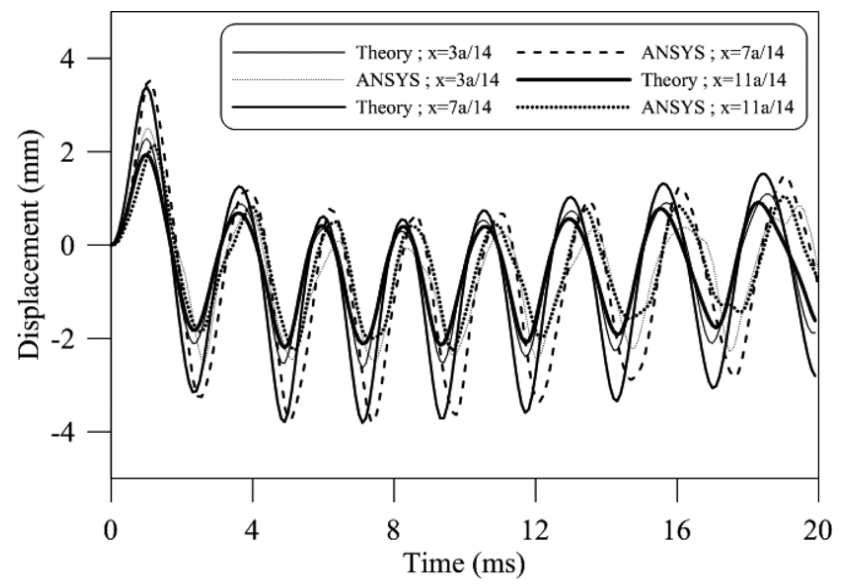

Fig. 19. The displacement-time histories of the simply-supported tapered laminated plates $(\beta=1.2)$ for the stacking sequence $[\mathrm{UCBGBC}]_{S}$ with $[45 / 0 / 45]_{S}$.

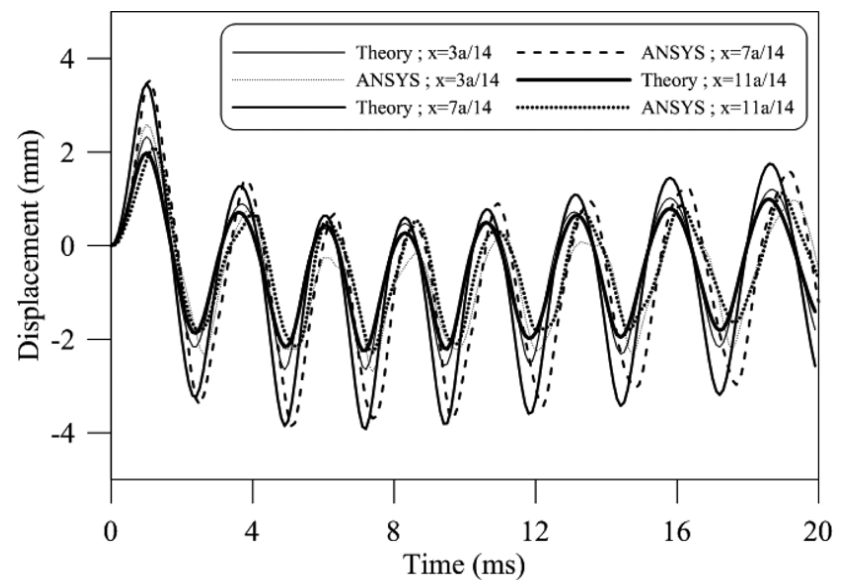

Fig. 20. The displacement-time histories of the simply-supported tapered laminated plates $(\beta=1.2)$ for the stacking sequence $[\mathrm{UCBGBC}]_{S}$ with $[60 / 30 / 0]_{S}$. 


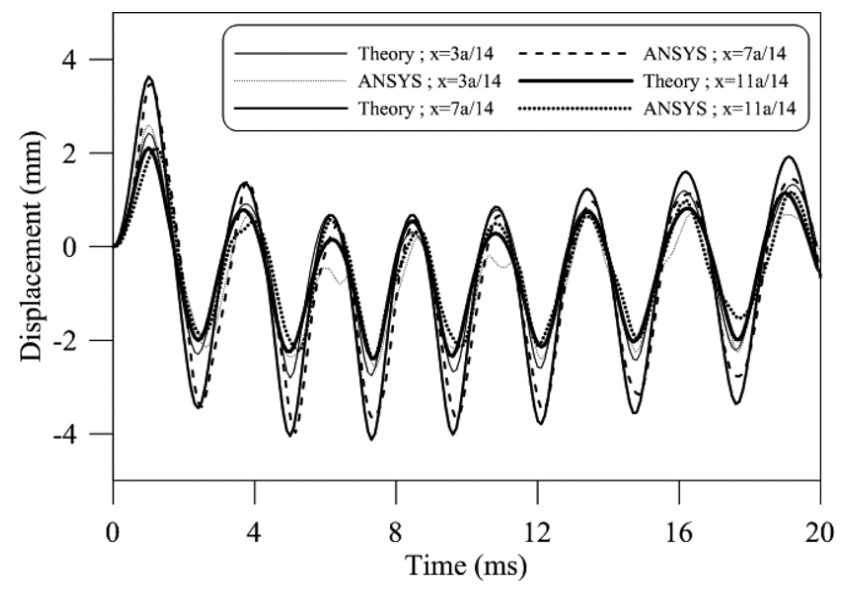

Fig. 21. The displacement-time histories of the simply-supported tapered laminated plates $(\beta=1.2)$ for the stacking sequence $[\mathrm{UCBGBC}]_{S}$ with $[90 / 0 / 90]_{S}$.

The minimum deflection and strain are obtained for the taper ratio of $\beta=0.2$. The maximum discrepancy between two methods occurs for the negative peak value of [UCBGBC] $]_{s}$ plate with the taper ratio of $\beta=1.2$ at the point of $x=11 a / 14$. These results show that the predicted values are becoming closer to the FEM results as the taper ratio is decreased. The predicted peak values of strains by using the present method are found to be slightly higher for the point of $x=11 a / 14$.

The effect of fiber orientation angle is also investigated. For this purpose, the analyses are performed for angle ply $\left([45 / 0 / 45]_{s}\right.$ and $\left.[60 / 30 / 0]_{s}\right)$ and cross ply ([90/0/90]) laminates for $\beta=1.2$. The displacement - time histories for these cases are given in from Figs 19 to 21 . The displacement-time histories of the selected points through the central axis obtained by using closed form solution are found to be in an agreement with the FEM results. The changing the fiber orientation angle slightly effected the results. The minimum positive and negative peak deflections are obtained for fiber orientation angle of $[45 / 0 / 45]_{s}$.

\section{Conclusion}

The transient analysis of tapered laminated composite plates is achieved using a closed form solution and FEM. The deflection and the strains are obtained in the tapered directions. The predicted displacement-time and strain-time histories by using the closed form solution are compared to the finite element results and an agreement is found between the two methods. The present method is capable of predicting the dynamic response of both flat and tapered plates subjected to the air blast loading. The predicted values of displacements and strains for the thicker part of the plate are found to be slightly higher than the FEM results. This is the result of solution functions chosen for the in-plane and out-of-plane deformations. In this study, in-plane deformations are described by using only the first term of the series solution. The solution function with one term cannot define the in-plane deformation exactly. This can be a reason for the difference between two methods for the thicker section of the plate. The closed form solution presented here costs much lower computer time compared to the FEM. The minimum deflection and strain are obtained for the $[\mathrm{BCUCBG}]_{s}$ plate and a taper ratio of $\beta=0.2$. However, the differences in the deflections for flat and tapered plates are small. In this study, the blast pressure is uniformly distributed on the plate. In case of nonuniform distribution, the tapered plate could be designed so that the thicker part is subjected to high pressure load and the thinner part is subjected to low pressure load. Therefore, in nonuniform pressure distribution, using the tapered plates could be advantageous. The thickness variation is taken as a linear function of coordinate axis in this study. However, the thickness variation could be taken as the second or third degree functions of coordinate axis. Besides, the material nonlinearities and damping are not taken into account in this study. These will be the subject of future studies. 


\section{Appendix}

The explicit expressions of the operators:

$$
\begin{aligned}
& L_{11}=-A_{11} \frac{\partial^{2}}{\partial x^{2}}-2 A_{16} \frac{\partial^{2}}{\partial x \partial y}-A_{66} \frac{\partial^{2}}{\partial y^{2}}, \\
& L_{12}=-\left(A_{12}+A_{66}\right) \frac{\partial^{2}}{\partial x \partial y}-A_{16} \frac{\partial^{2}}{\partial x^{2}}-A_{26} \frac{\partial^{2}}{\partial y^{2}}, \\
& L_{13}=3 B_{16} \frac{\partial^{3}}{\partial x^{2} \partial y}+\left(B_{12}+2 B_{66}\right) \frac{\partial^{3}}{\partial x \partial y^{2}}+B_{11} \frac{\partial^{3}}{\partial x^{3}}+B_{26} \frac{\partial^{3}}{\partial y^{3}}, \\
& L_{21}=-\left(A_{12}+A_{66}\right) \frac{\partial^{2}}{\partial x \partial y}-A_{16} \frac{\partial^{2}}{\partial x^{2}}-A_{26} \frac{\partial^{2}}{\partial y^{2}}, \\
& L_{22}=-A_{66} \frac{\partial^{2}}{\partial x^{2}}-A_{22} \frac{\partial^{2}}{\partial y^{2}}-2 A_{26} \frac{\partial^{2}}{\partial x \partial y}, \\
& L_{23}=\left(B_{12}+2 B_{66}\right) \frac{\partial^{3}}{\partial y \partial x^{2}}+B_{22} \frac{\partial^{3}}{\partial y^{3}}+3 B_{26} \frac{\partial^{3}}{\partial x \partial y^{2}}+B_{16} \frac{\partial^{3}}{\partial x^{3}}, \\
& L_{31}=-B_{11} \frac{\partial^{3}}{\partial x^{3}}-3 B_{16} \frac{\partial^{3}}{\partial x^{2} \partial y}-\left(B_{12}+2 B_{66}\right) \frac{\partial^{3}}{\partial x \partial y^{2}}-B_{26} \frac{\partial^{3}}{\partial y^{3}} \\
& L_{32}=-B_{16} \frac{\partial^{3}}{\partial x^{3}}-\left(B_{12}+2 B_{66}\right) \frac{\partial^{3}}{\partial x^{2} \partial y}-3 B_{26} \frac{\partial^{3}}{\partial x \partial y^{2}}-B_{22} \frac{\partial^{3}}{\partial y^{3}} \\
& L_{33}=D_{11} \frac{\partial}{\partial x^{4}}+4 D_{16} \frac{\partial^{4}}{\partial x^{3} \partial y}+\left(2 D_{12}+4 D_{66}\right) \frac{\partial^{4}}{\partial x^{2} \partial y^{2}}+4 D_{26} \frac{\partial^{4}}{\partial x \partial y^{3}}+D_{22} \frac{\partial^{4}}{\partial y^{4}} \\
& N_{1}\left(w^{0}\right)=-A_{11} \frac{\partial w^{0}}{\partial x} \frac{\partial^{2} w^{0}}{\partial x^{2}}-\left(A_{12}+A_{66}\right) \frac{\partial w^{0}}{\partial y} \frac{\partial^{2} w^{0}}{\partial x \partial y}-A_{16} \frac{\partial w^{0}}{\partial y} \frac{\partial^{2} w^{0}}{\partial x^{2}} \\
& -2 A_{16} \frac{\partial w^{0}}{\partial x} \frac{\partial^{2} w^{0}}{\partial x \partial y}-A_{26} \frac{\partial w^{0}}{\partial y} \frac{\partial^{2} w^{0}}{\partial y^{2}}-A_{66} \frac{\partial w^{0}}{\partial x} \frac{\partial^{2} w^{0}}{\partial y^{2}}
\end{aligned}
$$$$
N_{2}\left(w^{0}\right)=-\left(A_{12}+A_{66}\right) \frac{\partial w^{0}}{\partial x} \frac{\partial^{2} w^{0}}{\partial x \partial y}-A_{22} \frac{\partial w^{0}}{\partial y} \frac{\partial^{2} w^{0}}{\partial y^{2}}-2 A_{26} \frac{\partial w^{0}}{\partial y} \frac{\partial^{2} w^{0}}{\partial x \partial y}-A_{26} \frac{\partial w^{0}}{\partial x} \frac{\partial^{2} w^{0}}{\partial y^{2}}
$$$$
-A_{16} \frac{\partial w^{0}}{\partial x} \frac{\partial^{2} w^{0}}{\partial x^{2}}-A_{66} \frac{\partial w^{0}}{\partial y} \frac{\partial^{2} w^{0}}{\partial x^{2}}
$$

$$
\begin{aligned}
N_{3}\left(u^{0}, v^{0}, w^{0}\right)= & 2\left(B_{66}-B_{12}\right)\left(\frac{\partial^{2} w^{0}}{\partial x \partial y}\right)^{2}+2\left(B_{12}-B_{66}\right)\left(\frac{\partial^{2} w^{0}}{\partial x^{2}} \frac{\partial^{2} w^{0}}{\partial y^{2}}\right)-A_{11}\left(\frac{\partial^{2} u^{0}}{\partial x^{2}} \frac{\partial w^{0}}{\partial x}\right) \\
& -\left(3 A_{11} / 2\right)\left(\frac{\partial w^{0}}{\partial x}\right)^{2} \frac{\partial^{2} w^{0}}{\partial x^{2}}-\left(A_{12}+A_{66}\right)\left(\frac{\partial^{2} v^{0}}{\partial y \partial x} \frac{\partial w^{0}}{\partial x}\right)-2 A_{66}\left(\frac{\partial w^{0}}{\partial y} \frac{\partial^{2} w^{0}}{\partial y \partial x} \frac{\partial w^{0}}{\partial x}\right) \\
& -2 A_{16}\left(\frac{\partial^{2} u^{0}}{\partial y \partial x} \frac{\partial w^{0}}{\partial x}\right)-A_{16}\left(\frac{\partial^{2} v^{0}}{\partial x^{2}} \frac{\partial w^{0}}{\partial x}\right)-3 A_{16}\left(\frac{\partial^{2} w^{0}}{\partial x^{2}} \frac{\partial w^{0}}{\partial y} \frac{\partial w^{0}}{\partial x}\right) \\
& -3 A_{16}\left(\frac{\partial w^{0}}{\partial x}\right)^{2} \frac{\partial^{2} w^{0}}{\partial y \partial x}-A_{26}\left(\frac{\partial^{2} v^{0}}{\partial y^{2}} \frac{\partial w^{0}}{\partial x}\right)-4 A_{26}\left(\frac{\partial w^{0}}{\partial y} \frac{\partial^{2} w^{0}}{\partial y^{2}} \frac{\partial w^{0}}{\partial x}\right)
\end{aligned}
$$




$$
\begin{aligned}
& -A_{66}\left(\frac{\partial^{2} u^{0}}{\partial y^{2}} \frac{\partial w^{0}}{\partial x}\right)-\left(A_{66}+A_{12} / 2\right)\left(\frac{\partial w^{0}}{\partial x}\right)^{2} \frac{\partial^{2} w^{0}}{\partial y^{2}}-\left(A_{12}+A_{66}\right)\left(\frac{\partial^{2} u^{0}}{\partial x \partial y} \frac{\partial w^{0}}{\partial y}\right) \\
& -A_{22}\left(\frac{\partial^{2} v^{0}}{\partial y^{2}} \frac{\partial w^{0}}{\partial y}\right)-\left(3 A_{22} / 2\right)\left(\frac{\partial w^{0}}{\partial y}\right)^{2} \frac{\partial^{2} w^{0}}{\partial y^{2}}-A_{26}\left(\frac{\partial^{2} u^{0}}{\partial y^{2}} \frac{\partial w^{0}}{\partial y}\right) \\
& -2 A_{26}\left(\frac{\partial^{2} v^{0}}{\partial x \partial y} \frac{\partial w^{0}}{\partial y}\right)-3 A_{26}\left(\frac{\partial^{2} w^{0}}{\partial x \partial y}\right)\left(\frac{\partial w^{0}}{\partial y}\right)^{2}-A_{16}\left(\frac{\partial^{2} u^{0}}{\partial x^{2}} \frac{\partial w^{0}}{\partial y}\right) \\
& -A_{66}\left(\frac{\partial^{2} v^{0}}{\partial x^{2}} \frac{\partial w^{0}}{\partial y}\right)-\left(A_{66}+A_{12} / 2\right)\left(\frac{\partial w^{0}}{\partial y}\right)^{2} \frac{\partial^{2} w^{0}}{\partial x^{2}}-A_{11}\left(\frac{\partial^{2} w^{0}}{\partial x^{2}} \frac{\partial u^{0}}{\partial x}\right) \\
& -A_{12}\left(\frac{\partial v^{0}}{\partial y} \frac{\partial^{2} w^{0}}{\partial x^{2}}\right)-A_{16}\left(\frac{\partial u^{0}}{\partial y} \frac{\partial^{2} w^{0}}{\partial x^{2}}\right)-A_{16}\left(\frac{\partial v^{0}}{\partial x} \frac{\partial^{2} w^{0}}{\partial x^{2}}\right)-A_{12}\left(\frac{\partial u^{0}}{\partial x} \frac{\partial^{2} w^{0}}{\partial y^{2}}\right) \\
& -A_{22}\left(\frac{\partial v^{0}}{\partial y} \frac{\partial^{2} w^{0}}{\partial y^{2}}\right)-A_{26}\left(\frac{\partial u^{0}}{\partial y} \frac{\partial^{2} w^{0}}{\partial y^{2}}\right)-A_{26}\left(\frac{\partial v^{0}}{\partial x} \frac{\partial^{2} w^{0}}{\partial y^{2}}\right)-2 A_{16}\left(\frac{\partial u^{0}}{\partial x} \frac{\partial^{2} w^{0}}{\partial x \partial y}\right) \\
& -A_{26}\left(\frac{\partial v^{0}}{\partial y} \frac{\partial^{2} w^{0}}{\partial x \partial y}\right)-2 A_{66}\left(\frac{\partial u^{0}}{\partial y} \frac{\partial^{2} w^{0}}{\partial x \partial y}\right)-2 A_{66}\left(\frac{\partial v^{0}}{\partial x} \frac{\partial^{2} w^{0}}{\partial x \partial y}\right)
\end{aligned}
$$

Coefficients shown in the time-dependent nonlinear differential equations:

$$
\begin{aligned}
a_{0}= & \frac{a b^{9} h_{0}(2+\beta) \rho}{2520}, a_{1}=\frac{b^{7}\left(3 a^{2} A_{66}+A_{11} b^{2} \pi^{2}\right)(2+\beta)}{630 a} \\
a_{2}= & \frac{9 a^{4}\left(A_{12}+A_{66}\right) b^{4}(2+\beta)}{2 \pi^{6}} \\
a_{3}= & \frac{b^{3}\left(225 A_{11} b^{2} \pi^{2}\left(45+\pi^{4}\right)(2+\beta)-225 a^{2} \pi^{2}\left(-90 A_{66}+A_{12}\left(-45+\pi^{4}\right)\right)(2+\beta)\right)}{108000 a^{2} \pi^{3}} \\
a_{4}= & \frac{b^{3}\left(-6784 A_{11} b^{2}\left(45+\pi^{4}\right) \beta+1792 a^{2}\left(-90 A_{66}+A_{12}\left(-45+\pi^{4}\right)\right) \beta\right)}{108000 a^{2} \pi^{3}}, a_{5}=0 \\
b_{0}= & \frac{a^{9} b h_{0}(2+\beta) \rho}{2520}, b_{1}=\frac{a^{7}\left(3 A_{66} b^{2}+a^{2} A_{22} \pi^{2}\right)(2+\beta)}{630 b} b_{2}=\frac{9 a^{4}\left(A_{12}+A_{66}\right) b^{4}(2+\beta)}{2 \pi^{6}} \\
b_{3}= & \frac{a^{3}}{622080 b^{2} \pi^{3}}\left(1296 a^{2} A_{22} \pi^{2}\left(45+\pi^{4}\right)(2+\beta)-4 b^{2}\left(-29160 A_{66} \pi^{2}(2+\beta)\right.\right. \\
& \left.\left.+324 A_{12} \pi^{2}\left(-45+\pi^{4}\right)(2+\beta)\right)\right) \\
b_{4}= & \frac{a^{3}}{622080 b^{2} \pi^{3}}\left(81 a^{2} A_{22} \pi^{2}\left(45+16 \pi^{4}\right)(2+\beta)-4 b^{2}\left(-7290 A_{66} \pi^{2}(2+\beta)\right.\right. \\
& \left.\left.+81 A_{12} \pi^{2}\left(-45+16 \pi^{4}\right)(2+\beta)\right)\right) \\
b_{5}= & \frac{a^{3}}{622080 b^{2} \pi^{3}}\left(a^{2} A_{22}\left(-37273600 \beta+3686400 \pi^{2} \beta\right)-4 b^{2}\left(-90 A_{66}(-51200 \beta\right.\right. \\
& \left.\left.\left.+4608 \pi^{2} \beta\right)+A_{12}\left(-18688000 \beta+1889280 \pi^{2} \beta\right)\right)\right) \\
b_{6}= & 0, \\
c_{0}= & \frac{1}{8} a b h_{0}(2+\beta) \rho+27 a^{4} D_{22} \pi^{2}(2+\beta)\left(-3 \beta^{2}+\pi^{2}(2+\beta(2+\beta))\right) \\
& \left.+54 a^{2} b^{2}\left(D_{12}+2 D_{66}\right) \pi^{2}(2+\beta)\left(-3 \beta^{2}+\pi^{2}(2+\beta(2+\beta))\right)\right)
\end{aligned}
$$




$$
\begin{aligned}
& c_{1}=\frac{1}{5184 a^{3} b^{3}}\left(27 b^{4} D_{11} \pi^{2}(2+\beta)\left(-3 \beta^{2}+\pi^{2}(2+\beta(2+\beta))\right)\right. \\
& c_{2}=\frac{1}{381024000 a^{3} b^{3} \pi^{3}}\left(13395375 a^{4} A_{22} \pi^{7}(2+\beta)+13395375 A_{11} b^{4} \pi^{7}(2+\beta)\right. \\
& \left.+270 a^{2} b^{2} \pi^{5}\left(33075 A_{12} \pi^{2}(2+\beta)+44100 A_{66} \pi^{2}(2+\beta)\right)\right) \\
& c_{3}=\frac{1}{5184 a^{3} b^{3}}\left(b^{4} D_{11}\left(20480 \beta^{3}-4608 \pi^{2} \beta(2+\beta(2+\beta))\right)\right. \\
& +2 a^{2} b^{2}\left(D_{12}+2 D_{66}\right)\left(5120 \beta^{3}-1152 \pi^{2} \beta(2+\beta(2+\beta))\right) \\
& \left.+a^{4} D_{22}\left(1280 \beta^{3}-288 \pi^{2} \beta(2+\beta(2+\beta))\right)\right) \\
& c_{4}=\frac{1}{381024000 a^{3} b^{3} \pi^{3}}\left(-47278080 a^{4} A_{22} \pi^{5} \beta-778844160 A_{11} b^{4} \pi^{5} \beta\right. \\
& \left.+270 a^{2} b^{2} \pi^{5}\left(-473856 A_{12} \beta-627200 A_{66} \beta\right)\right) \\
& c_{5}=\frac{1}{381024000 a^{3} b^{3} \pi^{3}}\left(1587600 a A_{11} b^{8} \pi^{2}\left(45+\pi^{4}\right)(2+\beta)\right. \\
& \left.-1587600 a^{3} b^{6} \pi^{2}\left(-90 A_{66}+A_{12}\left(-45+\pi^{4}\right)\right)(2+\beta)\right) \\
& c_{6}=\frac{1}{381024000 a^{3} b^{3} \pi^{3}}\left(1587600 a^{8} A_{22} b \pi^{2}\left(45+\pi^{4}\right)(2+\beta)\right. \\
& \left.-19600 a^{6} b^{3}\left(-7290 A_{66} \pi^{2}(2+\beta)+81 A_{12} \pi^{2}\left(-45+\pi^{4}\right)(2+\beta)\right)\right) \\
& c_{7}=\frac{\left(-3612672 a A_{11} b^{8}\left(45+\pi^{4}\right) \beta-451584 a^{3} b^{6}\left(-90 A_{66}+A_{12}\left(-45+\pi^{4}\right)\right) \beta\right)}{381024000 a^{3} b^{3} \pi^{3}} \\
& c_{8}=\frac{1}{381024000 a^{3} b^{3} \pi^{3}}\left(19600 a^{8} A_{22} b\left(-1164800 \beta+115200 \pi^{2} \beta\right)\right. \\
& \left.-19600 a^{6} b^{3}\left(-270 A_{66}\left(-1280 \beta+128 \pi^{2} \beta\right)+A_{12}\left(-2800640 \beta+273600 \pi^{2} \beta\right)\right)\right) \\
& c_{9}=\frac{1}{381024000 a^{3} b^{3} \pi^{3}}\left(26790750 a^{4} A_{22} \pi^{7}(2+\beta)+107163000 A_{11} b^{4} \pi^{7}(2+\beta)\right. \\
& \left.+270 a^{2} b^{2} \pi^{5}\left(231525 A_{12} \pi^{2}(2+\beta)+286650 A_{66} \pi^{2}(2+\beta)\right)\right) \\
& c_{10}=\frac{1}{381024000 a^{3} b^{3} \pi^{3}}\left(-91445760 a^{4} A_{22} \pi^{5} \beta-411505920 A_{11} b^{4} \pi^{5} \beta\right. \\
& \left.+270 a^{2} b^{2} \pi^{5}\left(-366912 A_{12} \beta-545664 A_{66} \beta\right)\right) \\
& c_{11}=-\frac{4 a b}{\pi^{2}} q_{z}, d_{0}=\frac{1}{8} a b h_{0}(2+\beta) \rho \\
& d_{1}=\frac{1}{20736 a^{3} b^{3}}\left(432 b^{4} D_{11} \pi^{2}(2+\beta)\left(-3 \beta^{2}+4 \pi^{2}(2+\beta(2+\beta))\right)\right. \\
& +27 a^{4} D_{22} \pi^{2}(2+\beta)\left(-3 \beta^{2}+4 \pi^{2}(2+\beta(2+\beta))\right) \\
& \left.+216 a^{2} b^{2}\left(D_{12}+2 D_{66}\right) \pi^{2}(2+\beta)\left(-3 \beta^{2}+4 \pi^{2}(2+\beta(2+\beta))\right)\right)
\end{aligned}
$$




$$
\begin{aligned}
& d_{2}=\frac{1}{381024000 a^{3} b^{3} \pi^{3}}\left(13395375 a^{4} A_{22} \pi^{7}(2+\beta)+214326000 A_{11} b^{4} \pi^{7}(2+\beta)\right. \\
& \left.+270 a^{2} b^{2} \pi^{5}\left(132300 A_{12} \pi^{2}(2+\beta)+176400 A_{66} \pi^{2}(2+\beta)\right)\right) \\
& d_{3}=\frac{1}{20736 a^{3} b^{3}}\left(a^{4} D_{22}\left(5120 \beta^{3}-1152 \pi^{2} \beta(2+\beta(2+\beta))\right)\right. \\
& +8 a^{2} b^{2}\left(D_{12}+2 D_{66}\right)\left(1280 \beta^{3}-288 \pi^{2} \beta(2+\beta(2+\beta))\right) \\
& \left.+16 b^{4} D_{11}\left(320 \beta^{3}-72 \pi^{2} \beta(2+\beta(2+\beta))\right)\right) \\
& d_{4}=\frac{1}{381024000 a^{3} b^{3} \pi^{3}}\left(-30481920 a^{4} A_{22} \pi^{5} \beta-99066240 A_{11} b^{4} \pi^{5} \beta\right. \\
& \left.+270 a^{2} b^{2} \pi^{5}\left(-159936 A_{12} \beta-156800 A_{66} \beta\right)\right) \\
& d_{5}=\frac{1}{381024000 a^{3} b^{3} \pi^{3}}\left(99225 a^{8} A_{22} b \pi^{2}\left(45+16 \pi^{4}\right)(2+\beta)\right. \\
& \left.-4900 a^{6} b^{3}\left(-7290 A_{66} \pi^{2}(2+\beta)+81 A_{12} \pi^{2}\left(-45+16 \pi^{4}\right)(2+\beta)\right)\right) \\
& d_{6}=\frac{\left(-23933952 a A_{11} b^{8}\left(45+\pi^{4}\right) \beta+451584 a^{3} b^{6}\left(90 A_{66}-A_{12}\left(-45+\pi^{4}\right)\right) \beta\right)}{381024000 a^{3} b^{3} \pi^{3}} \\
& d_{7}=\frac{1}{381024000 a^{3} b^{3} \pi^{3}}\left(1225 a^{8} A_{22} b\left(-18636800 \beta+1843200 \pi^{2} \beta\right)\right. \\
& \left.-4900 a^{6} b^{3}\left(-270 A_{66}\left(-5120 \beta+512 \pi^{2} \beta\right)+A_{12}\left(-8407040 \beta+864000 \pi^{2} \beta\right)\right)\right) \\
& d_{8}=\frac{1}{381024000 a^{3} b^{3} \pi^{3}}\left(26790750 a^{4} A_{22} \pi^{7}(2+\beta)+107163000 A_{11} b^{4} \pi^{7}(2+\beta)\right. \\
& \left.+270 a^{2} b^{2} \pi^{5}\left(99225 A_{12} \pi^{2}(2+\beta)+154350 A_{66} \pi^{2}(2+\beta)\right)\right) \\
& d_{9}=\frac{1}{381024000 a^{3} b^{3} \pi^{3}}\left(-141834240 a^{4} A_{22} \pi^{5} \beta-1095482880 A_{11} b^{4} \pi^{5} \beta\right. \\
& \left.+270 a^{2} b^{2} \pi^{5}\left(-1043712 A_{12} \beta-1396224 A_{66} \beta\right)\right) \\
& d_{10}=0
\end{aligned}
$$

Coefficients shown in the finite difference equations:

$$
\begin{aligned}
& A_{1}=\frac{a_{0}}{(\Delta t)^{2}}+a_{1}, \quad A_{2}=a_{2}, \quad A_{3}=a_{3} W_{1}^{n}, \quad A_{4}=a_{4} W_{1}^{n}, \quad A_{5}=\frac{a_{0}}{\Delta t} \dot{U}^{n}+\frac{a_{0}}{(\Delta t)^{2}} U^{n}-a_{5} \\
& B_{1}=b_{2}, \quad B_{2}=\frac{b_{0}}{(\Delta t)^{2}}+b_{1}, \quad B_{3}=b_{3} W_{1}^{n}, \quad B_{4}=b_{5} W_{1}^{n}+b_{4} W_{2}^{n} \\
& B_{5}=\frac{b_{0}}{\Delta t} \dot{V}^{n}+\frac{b_{0}}{(\Delta t)^{2}} V^{n}-b_{6} \\
& C_{1}=c_{5} W_{1}^{n}+c_{7} W_{2}^{n}, \quad C_{2}=c_{6} W_{1}^{n}+c_{8} W_{2}^{n}, \quad C_{3}=\frac{c_{0}}{(\Delta t)^{2}}+c_{1}+c_{2}\left(W_{1}^{n}\right)^{2}+c_{9}\left(W_{2}^{n}\right)^{2} \\
& C_{4}=c_{3}+c_{4}\left(W_{2}^{n}\right)^{2}+c_{10}\left(W_{1}^{n}\right)^{2}, \quad C_{5}=\frac{c_{0}}{\Delta t} \dot{W}_{1}^{n}+\frac{c_{0}}{(\Delta t)^{2}} W_{1}^{n}+c_{11} \\
& D_{1}=d_{6} W_{1}^{n}, \quad D_{2}=d_{7} W_{1}^{n}+d_{5} W_{2}^{n}, \quad D_{3}=d_{3}+d_{4}\left(W_{1}^{n}\right)^{2}+d_{9}\left(W_{2}^{n}\right)^{2}
\end{aligned}
$$




$$
\begin{aligned}
D_{4}= & \frac{d_{0}}{(\Delta t)^{2}}+d_{1}+d_{2}\left(W_{2}^{n}\right)^{2}+d_{8}\left(W_{1}^{n}\right)^{2}, \quad D_{5}=\frac{d_{0}}{\Delta t} \dot{W}_{2}^{n}+\frac{d_{0}}{(\Delta t)^{2}} W_{2}^{n}+d_{10} \\
E_{1}= & \frac{B_{5} A_{1}-B_{1} A_{5}}{B_{2} A_{1}-B_{1} A_{2}}, \\
E_{2}= & \frac{B_{1} A_{3}-A_{1} B_{3}}{B_{2} A_{1}-B_{1} A_{2}}, \\
E_{3}= & \frac{B_{1} A_{4}-A_{1} B_{4}}{B_{2} A_{1}-B_{1} A_{2}} \\
F_{1}= & \frac{C_{5} A_{1}-C_{1} A_{5}+C_{1} A_{2} E_{1}-C_{2} A_{1} E_{1}}{C_{3} A_{1}-C_{1} A_{2} E_{2}-C_{1} A_{3}+C_{2} A_{1} E_{2}}, \\
F_{2}= & \frac{C_{1} A_{2} E_{3}+C_{1} A_{4}-C_{2} A_{1} E_{3}-C_{4} A_{1}}{C_{3} A_{1}-C_{1} A_{2} E_{2}-C_{1} A_{3}+C_{2} A_{1} E_{2}} \\
G_{1}= & A_{1} D_{4}-D_{1} A_{2} E_{2} F_{2}-D_{1} A_{2} E_{3}-D_{1} A_{3} F_{2}-D_{1} A_{4}+D_{2} A_{1} E_{2} F_{2}+D_{2} A_{1} E_{3}+D_{3} A_{1} F_{2} \\
G_{2}= & D_{5} A_{1}-D_{1} A_{5}+D_{1} A_{2} E_{1}+D_{1} A_{2} E_{2} F_{1}+D_{1} A_{3} F_{1}-D_{2} A_{1} E_{1}-D_{2} A_{1} E_{2} F_{1}-D_{3} A_{1} F_{1}
\end{aligned}
$$

\section{References}

[1] Z. Kazancı and Z. Mecitoğlu, Nonlinear dynamic behaviour of simply supported laminated composite plates subjected to blast load, $J$ Sound Vib 317 (2008), 883-897.

[2] Z. Kazancı and Z. Mecitoğlu, Nonlinear damped vibrations of a laminated composite plate subjected to blast load, AIAA J 44(9) (2006), 2002-2008.

[3] Z. Kazanc1, Z. Mecitoğlu and A. Hacıoğlu, Effect of In-Plane Stiffnesses and Inertias on Dynamic Behaviour of a Laminated Composite Plate under Blast Load, Proc. 9th Biennial ASCE Aerospace Division Int. Conf. on Engineering, Construction, and Operations in Challenging Environments, Houston, TX, (2004).

[4] L. Librescu, S.Y. Oh and J. Hohe, Linear and non-linear dynamic response of sandwich panels to blast loading, Composites: Part B (35) (2004), 673-683.

[5] H.S. Türkmen and Z. Mecitoğlu, Nonlinear structural response of laminated composite plates subjected to blast loading, AIAA $J$ 37(12) (1999), 1639-1647.

[6] H.S. Türkmen and Z. Mecitoğlu, Dynamic response of a stiffened laminated composite plate subjected to blast load, J Sound Vib 221(3) (1999), 371-389.

[7] A.L. Dobyns, Analysis of simply-supported orthotropic plates subject to static and dynamic loads, AIAA J (19) (1981), 642-650.

[8] L.A. Louca and Y.G. Pan, Response of stiffened and unstiffened plates subjected to blast loading, Eng Struct (20) (1998), 1079-1086.

[9] M. Amabili, Nonlinear vibrations of rectangular plates with different boundary conditions: Theory and experiments, Computers\&Struct (82) (2004), 2587-2605.

[10] M. Amabili, Theory and experiments for Large-Amplitude vibrations of rectangular plates with geometric imperfections, J Sound Vib (291) (2006), 539-565.

[11] G. Chandrasekharappa and H.R. Srirangarajan, Nonlinear response of elastic plates to pulse excitations, Computers\&Struct (27) (1987), $373-378$.

[12] V. Birman and C.W. Bert, Behaviour of laminated plates subjected to conventional blast, Int J Impact Engrg (6) (1987), 145-155.

[13] J. Chen, D.J. Dawe and S. Wang, Nonlinear transient analysis of rectangular composite laminated plates, Composite Struct (49) (2000), 129-139.

[14] Z. Kazancı and Z. Mecitoğlu, Nonlinear Dynamic Behaviour of a Laminated Composite Plate Subject to Blast Load for Different Boundary Conditions, Proc. 3rd Ankara Int. Aerospace Conf. (2005) Ankara, TR.

[15] Z. Kazanc1, Dynamic response of composite sandwich plates subjected to time-dependent pressure pulses, International Journal of Non-Linear Mechanics 46(5) (2011), 807-817.

[16] A.R. Kukreti, J. Farsa and C.W. Bert, Fundamental frequency analysis of tapered plates by differential quadrature, $J$ Eng Mech (118) (1992), 1221-1238.

[17] C.W. Bert and M. Malik, Free vibration analysis of tapered rectangular plates by differential quadrature method: A semi-analytical approach, J Sound Vib (190) (1996), 41-63.

[18] C.W. Bert and M. Malik, Semi-analytical differential quadrature solution for free vibration analysis of rectangular plates, AIAA $J$ (34) (1996), 601-606

[19] P. Malekzadeh, Nonlinear Free vibration of tapered mindlin plates with edges elastically restrained against rotation using DQM, Thin-Walled Struct (46) (2008), 11-26. 
[20] P. Malekzadeh and G. Karami, Large amplitude flexural vibration analysis of tapered plates with edges elastically restrained against rotation using DQM, Eng Struct (30) (2008), 2850-2858.

[21] O. Barton, Jr, Fundamental frequency of tapered plates by the method of eigensensitivity analysis, Ocean Engrg (26) (1999), 565-573.

[22] A.S. Ashour, A Semi-Analytical solution of the flexural vibration of orthotropic plates of variable thickness, J Sound Vib (240) (2001), 431-445.

[23] A.S. Ashour, Vibration of variable thickness plates with edges elastically restrained against translation and rotation, Thin-Walled Struct (42) (2004), 1-24.

[24] C.W. Bert and M. Malik, Differential quadrature method in computational mechanics: A review, Appl Mech Rev (49) (1996), 1-28.

[25] M. Malik and C.W. Bert, Implementing Multiple Boundary Conditions in the DQ Solution of Higher-Order PDE's: Application to Free Vibration of Plates, Int J Numer Methods Engrg (39) (1996), 1237-1258.

[26] Autar, K. Kaw, Mechanics of Composite Materials, CRC Press, 1997, pp. 109-113.

[27] Composite Materials Handbook, Volume 2, Polymer Matrix Composite Materials Properties, Department of Defence, Mil-HDBK-17-2F, USA, 2002 pp. 6-35-6-44, 4-152-4-162, 4-205-4-214. 

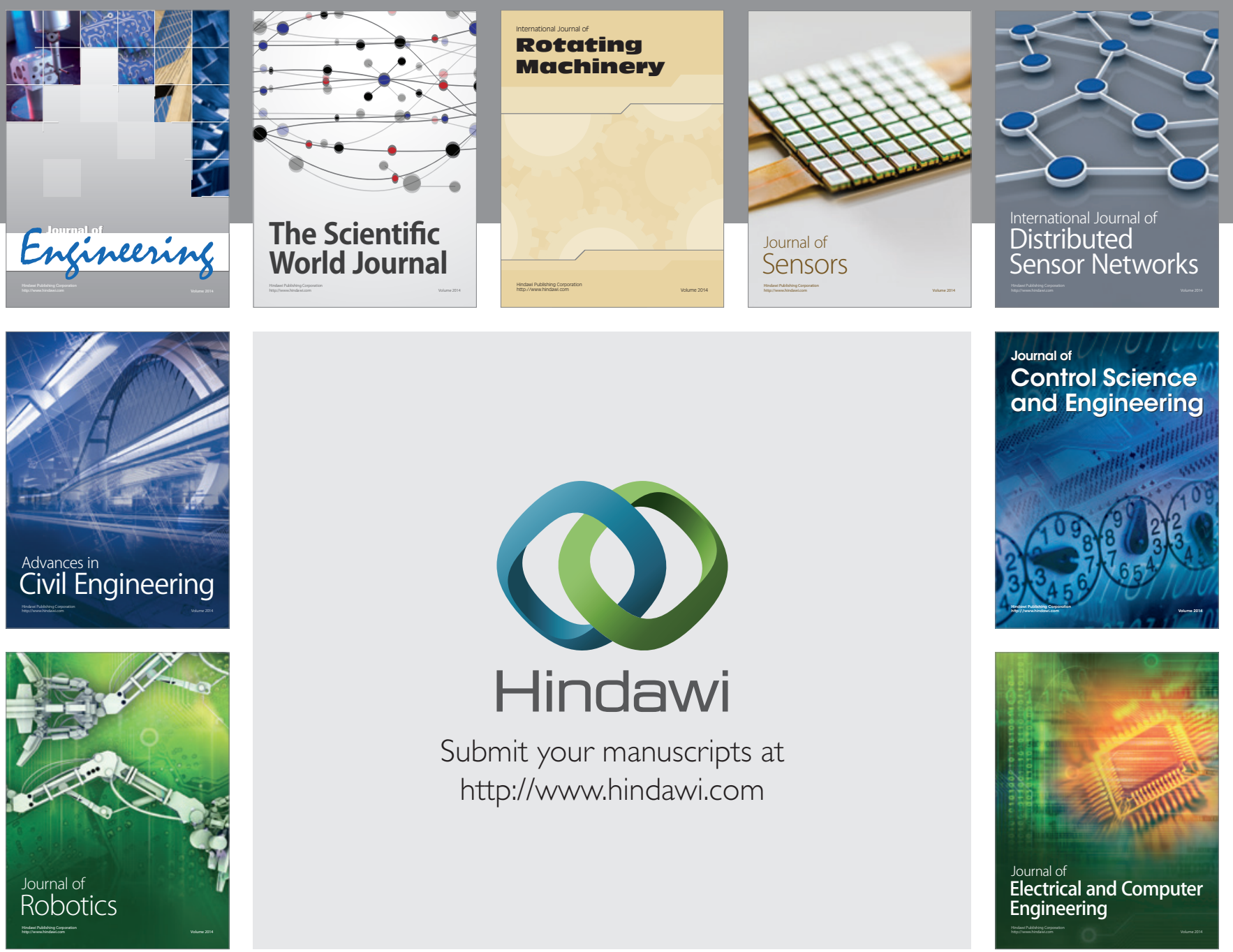

Submit your manuscripts at

http://www.hindawi.com
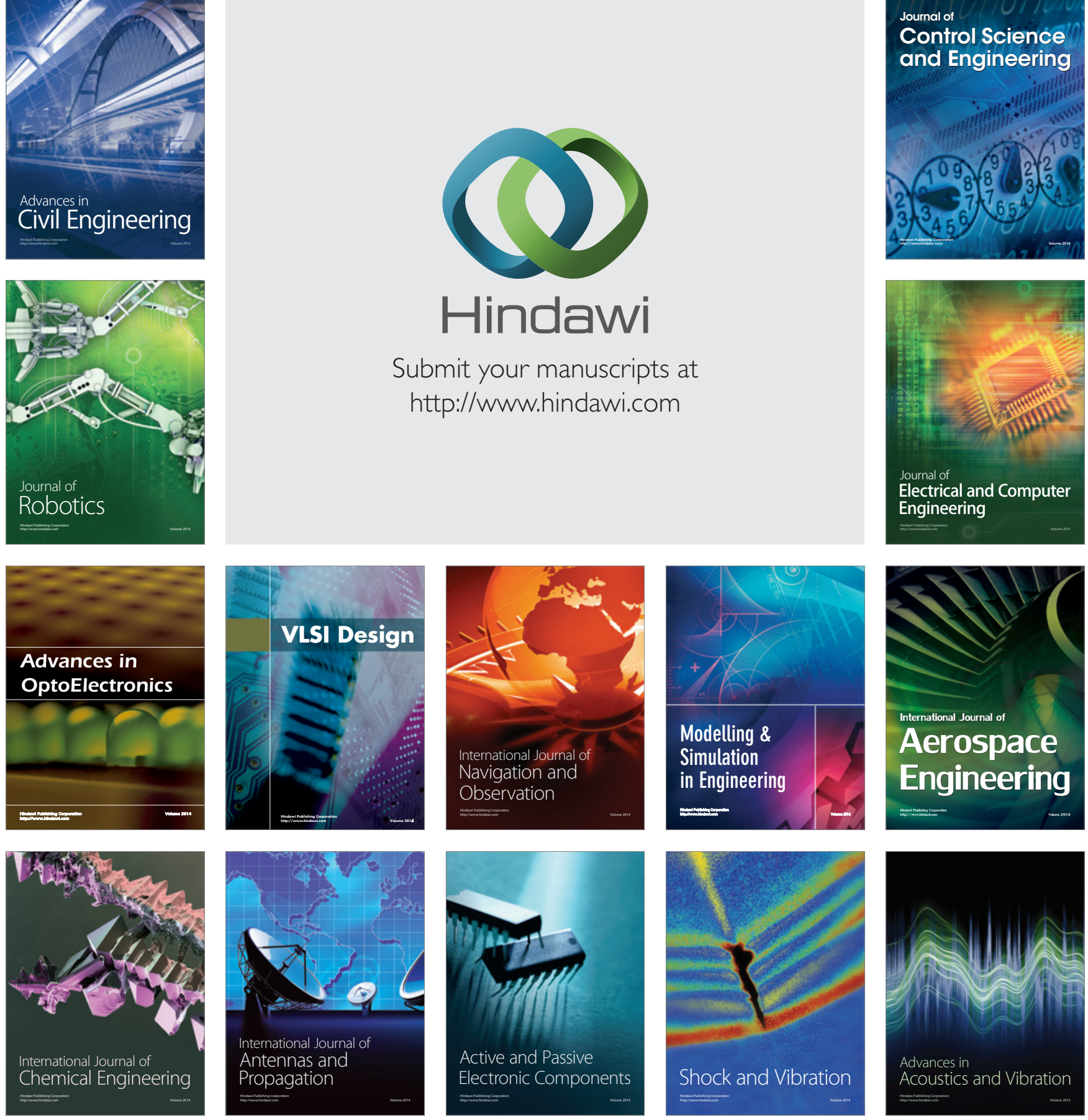